\title{
An interval programming based approach for fully uncertain resource- constrained project scheduling problem considering project manager's attitude toward risk
}

\author{
Tamamen belirsiz kaynak kısıtlı proje çizelgeleme problemi için proje \\ yöneticisinin riske karşı tutumunu dikkate alan aralık programlama \\ tabanlı bir yaklaşım
}

\author{
Kemal SUBULAN ${ }^{*}$ iD \\ ${ }^{1}$ Department of Industrial Engineering, Engineering Faculty, Dokuz Eylül University, Izmir, Turkey \\ kemal.subulan@gmail.com
}

Received/Geliș Tarihi: 09.08.2018, Accepted/Kabul Tarihi: 03.01.2019

* Corresponding author/Yazıșilan Yazar

doi: $10.5505 /$ pajes.2019.10734 Research Article/Araștırma Makalesi

\begin{abstract}
In recent years, there has been a growing attention to model and solve resource-constrained project scheduling problem (RCPSP) under uncertain environments. In most of the real-life cases, project managers may face with many uncertainties in activity durations, resource availabilities, resource requirements of the activities, the earliest and latest finishing times of the activities etc. In addition to these input parameters, project schedule which represents the starting and/or completion times of the activities should also be considered as uncertain variables in such a fully uncertain environments where all of the project data are imprecise. Based on this motivation, this paper presents an interval programming based transformation approach to overcome fully uncertain nature of the problem. In detail, classical discrete-time binary integer programming model of the deterministic problem was extended by incorporating interval-valued parameters and decision variables. Then, fully uncertain RCPSP was transformed into the crisp equivalent form by making use of interval programming, interval ranking and interval arithmetic operations. In the proposed approach, interval arithmetic operations are performed by using supplementary information obtained from the project manager. Thus, the proposed approach is also able to take into account the project managers' attitude toward risk and produces more acceptable and risk-free solutions. Finally, a real-life liquefied natural gas (LNG) storage tank construction project in a petroleum refinery is presented for testing its validity and practicality. The computational results have shown that more applicable and information efficient project schedules can be derived via the proposed approach according to the project manager's attitude toward risk.
\end{abstract}

Keywords: Resource-Constrained project scheduling, Interval programming, Risk attitude

\section{Introduction}

RCPSP is one of the widely studied combinatorial optimization problem in operations research and has a NP-hard nature to solve optimally. In most of the existing studies in the literature, project inputs are generally assumed to be deterministic and thus crisp project schedules are generated. However, projects are subject to considerable uncertainty in real-life settings. This uncertainty may come from several sources. The project scope may change, resources may become unavailable or weather conditions may cause delays to some of the activities [1] Moreover, exact duration of an activity may not be known precisely at the beginning of the project. Similarly, amount of
Öz

Son yıllarda, belirsizlik altında kaynak kısıtlı proje çizelgeleme problemlerinin modellenmesi ve çözümüne, giderek artan bir ilgi olduğu görülmektedir. Gerçek hayat uygulamalarının birçoğunda, proje yöneticileri, aktivite süreleri, kaynak kapasiteleri, aktivitelerin kaynak gereksinimleri ve en erken/en geç bitiş zamanlarının kesin ve net bir șekilde belirlenememesinden ötürü, birçok belirsizlik ile karșı karșlya kalmaktadır. Tüm bu parametrelerin belirsizlik içerdiği ortamlarda, aktivitelerin başlangıç veya bitiş zamanları olarak tanımlanan karar değișkenleri de kesin ve net bir șekilde belirlenememekte olup belirsizlik içerecektir. Bu araştırma motivasyonu ile bu çalışmada, aralık programlama tabanlı bir yaklașım önerilerek, tamamen belirsiz ortamlarda problemin çözümü gerçekleştirilmiştir. Daha ayrıntılı olarak, probleme ait klasik kesikli zamanlı ikili tamsayıl programlama modeli, aralık saylar ile ifade edilen parametre ve karar değişkenleri kullanılarak genişletilmiștir. Daha sonra, tamamen belirsiz kaynak kısitlı proje çizelgeleme problemine ait matematiksel formülasyon, aralık programlama, aralık siralama ve aralık aritmetik operasyonlar yardımıyla, belirlilik altındaki klasik eșdeğer forma dönüștürülmüștür. Önerilen yaklaşımda, aralık aritmetik operasyonlar, proje yöneticisinden elde edilen ek bilgiler yardımıyla gerçekleștirilmiștir. Bu sayede, proje yöneticilerinin riske karşı tutumları dikkate alınabilmekte ve riskten bağımsız, kabul edilebilir çözümler elde edilebilmektedir. Son olarak, önerilen yaklaşımın geçerliliğinin ve uygulanabilirliğinin test edilebilmesi için, bir petrol rafinerisindeki sıvılaştırılmış doğal gaz tankına ait inșaat projesine yer verilmiștir. Elde edilen sonuçlar göstermektedir ki, önerilen yaklaşım ile proje yöneticisinin riske karşı tutumu doğrultusunda, uygulanabilir ve bilgi etkin çözümler üretilebilmektedir.

Anahtar kelimeler: Kaynak kısıtlı proje çizelgeleme, Aralık programlama, Riske karșı tutum

the available sources may not be known before project execution. Briefly, uncertainties in the project parameters may be resulted from estimation errors, unforeseen weather conditions, late delivery of some required sources, unpredictable incidents such as accidents and breakdowns [2]. While dealing with the uncertainty of these project parameters, the usage of fuzzy set theory is preferred in this study instead of using a stochastic approach (or probability theory) and the uncertain project parameters/variables are represented by interval-valued numbers. Due to the uniqueness of some project cases, it may not be possible to generate probability distributions explicitly for the activity durations, resource requirements and capacities. Because, similar projects may 
have not been carried out previously. Therefore, uncertainty of the project parameters may not be handled by random variables due to the lack of statistical past data. In this case, fuzzy set theory may be a useful tool to study the project scheduling problems [3]. For this reason, fuzzy set theory can be easily utilized in such cases where the uncertain project parameters are estimated by project managers based on their expertise, knowledge and judgements. Such a human expertise on these uncertain parameters may generally involve ambiguous or vague information which cannot be modelled by using stochastic or probabilistic approaches. Moreover, as it was emphasized by Atli and Kahraman [3]-[4] that some of the stochastic project scheduling models are generally computationally too expensive and theoretically too complex. For this reason, it is difficult to apply them to solve practical large-scaled project scheduling problems. For all of these reasons, uncertain project parameters as well as the project schedules are represented by interval numbers in this study because of the ease of computation. In fact, interval numbers are very useful and the simplest technique for representing the uncertainty of project parameters. Moreover, different sources of information including objective/subjective and attitudinal character of the project manager can be easily reflected by interval numbers [5].

When all of the project parameters are inherently uncertain, solution to a fully uncertain RCPSP can no longer be represented as a single deterministic schedule. In other words, starting and finishing times of the project activities cannot be determined precisely. Therefore, activity schedules should also be considered as uncertain variables. For this reason, fuzzy or interval-valued project schedules may help the project managers to make more appropriate decisions by gathering all possible situations that could arise in the future. As also highlighted by Atli and Kahraman [3] that fuzzy schedules comprise multiple crisp schedules, the choice between which is at the discretion of management.

Based on this motivation, this paper addressed a fully uncertain RCPSP in which all of the project parameters and variables (activity schedules) are under uncertainty. The first aim of this paper is to develop a mathematical programming based solution approach for a RCPSP under fully uncertain environments. The second and maybe the most important aim of this paper is to take project manager's risk attitude into consideration while generating interval-valued project schedules. In majority of the existing studies, project manager's role and preferences are not taken into account during the project scheduling under resource allocation. Nevertheless, project manager's character and risk tolerance may be crucial under such a fully uncertain project planning environments. Actually, there are considerable effects of human factors and risk attitudes on the goals of practical project management. Because, several risky situations and questionable solutions may occur for real-life project scheduling settings with full of uncertainties. In this paper, four different risky situations in a RCPSP are handled and discussed in the later sections. In fact, these risky situations are resulted from uncertainties. For this reason, project manager's risk attitude should be considered while generating the project schedules. In detail, due to the response or state of the mind, which is orientated by naturally subjective insight, to a specified uncertain condition is dissimilar from one project manager to another, a suitable project schedule should be generated and offered to the project manager according to his/her risk tolerance [6]-[8]. Therefore, various crisp and interval-valued project schedules can be derived by using the proposed approach with respect to the risk-averse, partially risk-averse and risk-seeking project managers. To the best of our knowledge, there is no similar study in the literature which developed a transformation technique for solving such a fully uncertain RCPSP so far. Furthermore, there is a scarcity of researches in the literature on RCPSP that focused on the project managers' risk attitude.

The rest of this paper is organized as follows. A brief literature review on RCPSP under uncertainty is presented in Section 2. Basic definitions and preliminaries are given in Section 3. Section 4 presents the problem description, mathematical formulations and fundamentals of the proposed transformation approach. Risky situations in a RCPSP are also illustrated based on a numerical example in the same section. The computational results of the proposed approach over a real-life construction project are presented in Section 5. Finally, concluding remarks and future research directions are given in Section 6 .

\section{Related literature}

This section presents a brief literature survey on RCPSP under uncertainty. In fact, the recent studies in the literature are discussed and categorized in terms of the type of uncertainty, i.e., fuzzy, stochastic or fuzzy-stochastic project scheduling.

In the preliminary studies, uncertainty in the key project parameters was usually modelled by probability theory [9], [10]. In fact, activity durations were generally defined as random variables; they followed a known probability distribution and the objective was to minimize expected makespan. An overview of the recent articles which studied stochastic RCPSP can be summarized as follows: Artigues et al. [11] developed a robust optimization approach for a stochastic RCPSP by assuming that decision maker does not have an adequate confidence in the subjective probabilities associated with the possible activity durations. They proposed a scenario relaxation based heuristic for solution of large-scaled problem instances. Li and Womer [12] proposed a closed-loop approximate dynamic programming approach based on rollout policy for solving a reasonably large-sized RCPSP with stochastic task durations. A simulation-optimization approach which aims to minimize cost of a project was designed by Perez [13] to deal with the stochastic activity times of a RCPSP. Ashtiani et al. [14] presented a new class of pre-processor policies which integrated the elements of resource-based and the earliest-start policies for a stochastic RCPSP. Afterwards, new class of generalized preprocessor policies were also proposed by Rostami et al. [2] for a RCPSP with stochastic activity times. Then, in order to find high-quality solutions, a two-phase metaheuristic algorithm consisting of greedy randomized adaptive search procedure (GRASP) and genetic algorithm (GA) were employed. Wang et al. [15] built on an uncertain model based on a chance-constrained program to satisfy demand of a risk-averse project manager. They utilized a hybrid algorithm which combines GA and an uncertain serial SGS as a solution methodology. In order to measure the scheduling uncertainty related to evolution of a stochastic RCPSP, Tseng and Ko [16] presented a scenario-based approach with utility-entropy decision model. Creemers [17] developed a new continuous-time Markov chain and used a backward stochastic dynamic program for solution of a preemptive stochastic RCPSP with exponentially distributed activity durations. Six different heuristics were developed by Chakrabortty et al. [18] to incorporate random activity 
durations of a RCPSP as a deterministic constraint into a robust optimization model. Then, the resulting model was solved via a branch-and-cut algorithm. A two-stage mathematical program was formulated by Bruni et al. [19] for a robust RCPSP under polyhedral activity durations. A decomposition algorithm which separates the resource allocation from project scheduling was also designed. Bruni et al. [20] developed two exact decomposition approaches for a robust RCPSP under budgeted uncertainty polytope. While choosing the value for budget of uncertainty, risk-attitude of the decision maker was also considered. Chen et al. [1] evaluated the performance of several priority rule heuristics on large-scaled stochastic RCPSP instances. Most of these previously mentioned studies just concentrated on the stochastic activity durations. In addition to the uncertain activity times, Chand et al. [21] handled stochastic resource availabilities and applied a population-based evolutionary algorithm to find robust solutions. Uysal et al. [22] formulated a chance-constrained, piecewise-linear, mixed integer program (MIP) for a RCPSP with stochastic resource demands.

In many cases, due to the lack of statistical project data to obtain the probability distributions of project parameters, they are generally estimated by project planners based on their expertise and subjective judgments. Due to this fact that several researchers attempt to model and solve RCPSP under fuzzy environments. Fuzzy RCPSP was first addressed by Hapke et al. $[23],[24]$ and priority rule based serial and parallel scheduling procedures were extended to deal with fuzzy time parameters, i.e., activity durations, ready times and due dates. Özdamar and Alanya [25] proposed a generic heuristic algorithm based on priority rules for a RCPSP where task durations and start-tostart precedence relationships among the activities were represented by fuzzy numbers. Unlike the existing studies on fuzzy RCPSP, they also considered the uncertainty related to network topology. Another heuristic method which is named as fuzzy parallel scheduling was employed by Pan et al. [26] to solve a RCPSP with fuzzy durations. Pan and Yeh [27] also developed a fuzzy GA combined with Tabu mechanism for a fuzzy RCPSP in order to obtain an approximate optimal solution. Liu et al. [28] applied a genetic local search algorithm for solving fuzzy RCPSP with imprecise activity durations and resource constraints. Long and Ohsato [29] developed a fuzzy critical chain method for solving fuzzy RCPSP and added a project buffer to the end of the selected critical chain to deal with the uncertainty of activity durations. Bhaskar et al. [30] presented a non-recursive heuristic method which mainly depends on the priority rule for parallel schedule generation scheme (SGS) for a RCPSP with triangular fuzzy activity durations. Wang and Huang [31] formulated two fuzzy models for a RCPSP with minimum expected cost and maximum credibility under uncertain activity durations. They integrated fuzzy simulation and GA to solve these two types of fuzzy models. Atli and Kahraman [3] addressed RCPSP with fuzzy durations and utilized resource over time and minimum slack priority rules to obtain good initial solutions for the proposed modified Taboo search algorithm. Afterwards, Atli and Kahraman [4] also handled a multi-mode RCPSP with fuzzy activity durations and solved the realistic sized problem instances through an integrated taboo search and minimum slack priority scheduling algorithms. Kaveh et al. [32] applied relatively new metaheuristics namely charged system search (CSS) and colliding body optimization (CBO) for solving a reallife RCPSP with fuzzy activity durations. As mentioned previously, risk attitude of the project managers was rarely discussed in the literature. In a fuzzy multi-objective, multimode RCPSP, risk acceptance level and the optimism of the project managers were considered by Sajadi et al. [33] only.

Most of these former studies produced crisp activity schedules. However, for such a fully uncertain RCPSP where all of the project parameters are defined as uncertain data, activity schedules should also be uncertain in nature. Based on this motivation, some researchers took into consideration the uncertainty embedded in the project schedules and defined them as uncertain decision variables. For instance, a fuzzy beam search algorithm was developed by Wang [34] to generate a fuzzy project schedule where the schedule risks were also minimized. Wang [35] also proposed a GA based robust scheduling methodology to solve a RCPSP with fuzzy activity durations. As a final solution, they presented a fuzzy project schedule which assists the risk-averse project managers for minimizing the risk of the project of being late. Masmoudi and Hait [36] provided fuzzy project schedule for a RCPSP with fuzzy workload. In order to handle the fuzzy task presence and workload, they extended the parallel SGS of Hapke and Slowinski [24]. Zha and Zhang [37] investigated a fuzzy flexible RCPSP in which employees had multiple skills and can choose only one skill to apply to each assigned activity. In the solution phase, they only took into account the uncertainty of activity durations and employed GA so as to generate a fuzzy project schedule. Knyazeva et al. [38] also provided an uncertain project schedule including fuzzy starting and finishing times for a GIS software development project activities under resource allocation and uncertainty. Yousefli [39] proposed a fully fuzzy mathematical programming model for a RCPSP by considering the fuzzy scheduling concept. In detail, they calculated the activity schedule (starting and finishing times) as fuzzy numbers because of the uncertainty of all the project parameters. Due to the complexity of the proposed highly non-linear fuzzy mathematical program, a fuzzy ant colony optimization (ACO) algorithm was developed to solve large-scaled project instances. Subulan [6] also discussed fully uncertain nature of the RCPSP and developed an interval programming based transformation approach to produce flexible schedules for a real-life LNG storage tank construction project. In this paper, that transformation approach is extended by considering project manager's attitude toward risk. Actually, some risky situations in project scheduling are taken into account while generating intervalvalued project schedules. Moreover, Subulan [6] just considered manpower requirements as project resources. Fortunately, this paper is able to handle the uncertainty of both manpower and machinery requirements of an LNG tank construction project.

Because of the two types of common uncertainties, i.e. fuzziness and randomness in real-life applications, some researchers focused on modelling and solving hybrid fuzzy-random RCPSP. Nematian et al. [40] represented activity durations, ready-time and deadline of a project as fuzzy-random variables and developed a linearized MIP technique based on the expected value of fuzzy-random variables, fuzzy inequality approaches and max-min operator of [41]. A similar MIP based transformation process was also utilized by Artykov and Atymtayeva [42] by focusing on just fuzzy-random activity durations. A hybrid GA with fuzzy logic controller was employed by Xu and Zhang [43] for a multi-objective resourceconstrained multiple project scheduling problem. The resource 
consumptions and due-dates were defined as fuzzy-random variables. Gang et al. [44] developed a hybrid solution approach which combines adaptive Particle Swarm Optimization (PSO), hybrid GA and fuzzy-random simulation algorithms for a multiproject RCPSP with fuzzy-random activity durations and resource costs. A bi-level multi-objective PSO algorithm was designed by Zhang [45] for a fuzzy-random RCPSP with a complex hierarchical organization structure of upper and lower level decision makers. In addition to the activity durations and resource availabilities, tardiness penalty costs of the activities were taken as fuzzy-random data. Xu and Feng [46] developed a combinatorial-priority-based hybrid PSO algorithm for a multi-mode resource-constrained multiple project scheduling problem. The normal and crashed durations, variable and crashing costs and resource consumptions were represented by fuzzy-random variables. A proactive strategy was presented by Chen and Zhang [47] to formulate a robust optimization model of a preemption RCPSP with fuzzy-random activity durations and resource consumption. Apart from the former studies, they also considered activity splitting as well.

Finally, most of the above studies are summarized and classified in Table 1 with respect to the type of uncertainty, uncertain components of the stated problem and relevant solution methodology. As it is obviously seen from Table 1 that most of the existing researches in the literature focused on the crisp project schedules despite of the fully uncertain nature of the RCPSP. However, as mentioned earlier, project schedules or completion times of the activities should also be stated as uncertain variables and represented by intervals when all of the project data are imprecise. It should also be noted here that resource availabilities and consumptions of the activities were generally considered as crisp data by many former studies. Moreover, fuzzy, stochastic or fuzzy-stochastic project data are taken into account by the former studies to represent the uncertainty. According to Table 1, there has been an increasing interest in modeling and solving RCPSP under fuzzy-stochastic environments. In fact, fuzzy-random RCPSP have become a hot research topic nowadays. To the best of our knowledge, interval uncertainty and interval programming were not utilized in a RCPSP so far. The reasons behind the selection of interval type uncertainty are also mentioned before. Additionally, project managers' risk attitude and some risky situations in an uncertain RCPSP are rarely discussed by the previous researches. Moreover, priority rules and metaheuristics are the most commonly used solution methods since the NP-hard nature of the problem. However, developing mathematical programming based transformation approaches is a challenging task for RCPSP under uncertainty. Because, RCPSP may have a highly non-linear structure under fuzzy and/or stochastic environments. In detail, both of the NP-hard nature and highly non-linear structure of the uncertain RCPSP make it difficult to solve by mathematical programming. Fortunately, using interval numbers for dealing with uncertainties makes the usage of mathematical programming based approaches possible and easier way. This is the main research motivation of this paper.

Based on all of these motivations, the main contributions of this paper can be listed as follows:

I. A new transformation technique is developed to solve a fully uncertain RCPSP in which all of the project parameters (input data) as well as project schedules (outputs or decision variables) are represented by interval numbers. Instead of just a crisp project schedule, various interval-valued project schedules can be generated,

II. The proposed approach is able to handle project manager's attitude toward risk. In fact, various crisp and/or interval-valued project schedules can be generated by using the proposed approach with respect to the project manager's risk attitude. According to the computational study, relatively more precise project schedules with longer makespan are produced for riskaverse or partially risk-averse project managers. On the other hand, relatively shorter makespan but more imprecise completion time intervals (or project schedules) with high degree of uncertainty are obtained for risk-seekers. For a risk neutral project manager, completion time intervals of the activities may have relatively lower degree of uncertainty. In other words, lower and upper bounds of the completion time interval of an activity are close to each other,

III. The proposed approach can take into account different risky situations in an uncertain RCPSP. Four different risky situations are examined while transforming the interval program into its crisp equivalent form. Therefore, more reliable and information efficient project schedules can be generated for many real-life settings. Detailed explanations for these risky situations are given in Section 4.1 and they are also basically illustrated by a trivial numerical example in Section 4.2.

\section{Background and preliminaries}

In this section, some of the necessary background, definitions and fundamental notation regarding to interval numbers, interval arithmetic and ranking operations are presented.

Definition 1 Let A indicate a closed and bounded non-empty set of real numbers and $A^{ \pm}$represents an interval number with known upper and lower bounds $A^{-}$and $A^{+}$, respectively. Then, a non-negative interval number $A^{ \pm}=\left[A^{-}, A^{+}\right]$can be expressed as $A^{ \pm}=\left\{x \mid 0<A^{-} \leq x \leq A^{+}\right\}$or interval number can also be stated as $A^{\mp}=\left\{A^{-}+z\left(A^{+}-A^{-}\right) \mid 0 \leq z \leq 1\right\}$ by making use of an auxiliary variable $z$ that can be used to transform interval-valued parameter into a crisp one [48]-[50].

Definition 2 Two interval numbers $A^{ \pm}=\left[A^{-}, A^{+}\right]$and $B^{ \pm}=\left[B^{-}, B^{+}\right]$are said to be equal when the equality relation is satisfied. The equality relation for interval numbers can be defined as: $A^{ \pm}=B^{ \pm} \Leftrightarrow A^{-}=B^{-} \wedge A^{+}=B^{+}$[51].

Definition 3 For any two interval numbers $A^{ \pm}=\left[A^{-}, A^{+}\right]$and $B^{ \pm}=\left[B^{-}, B^{+}\right]$, let $* \in\{+,-, \times, \div\}$ be the binary algebraic operations are defined by $A^{ \pm} * B^{ \pm}=[\min \{A * B\}, \max \{A * B\}]$ where $A^{-} \leq A \leq A^{+}$and $B^{-} \leq B \leq B^{+}$[51],[52]. Some arithmetic operations on interval numbers are as follows:

$$
\begin{gathered}
A^{ \pm}+B^{ \pm}=\left[A^{-}+B^{-}, A^{+}+B^{+}\right] \\
A^{ \pm}-B^{ \pm}=\left[A^{-}+B^{+}, A^{+}+B^{-}\right] \\
A^{ \pm} \times B^{ \pm}=\left[A^{-} B^{-}, A^{+} B^{+}\right] \\
A^{ \pm} \div B^{ \pm}=\left[A^{-} / B^{+}, A^{+} / B^{-}\right] \\
c \times A^{ \pm}=\left[c A^{-}, c A^{+}\right] \text {if } c \geq 0 \\
c \times A^{ \pm}=\left[c A^{+}, c A^{-}\right] \text {if } c<0
\end{gathered}
$$


Table 1: An overview of the articles on RCPSP under uncertain environments.

\begin{tabular}{|c|c|c|c|c|c|c|c|}
\hline \multirow[t]{2}{*}{ Article } & \multirow{2}{*}{$\begin{array}{l}\text { Uncertain data } \\
\text { representation }\end{array}$} & \multicolumn{5}{|c|}{ Uncertain Components of RCPSP } & \multirow[b]{2}{*}{ Solution Methodology } \\
\hline & & $\begin{array}{c}\text { Activity } \\
\text { durations }\end{array}$ & $\begin{array}{c}\text { Resource } \\
\text { availability }\end{array}$ & $\begin{array}{c}\text { Resource } \\
\text { consumption } \\
\end{array}$ & $\begin{array}{c}\text { Project } \\
\text { schedule }\end{array}$ & $\begin{array}{l}\text { Precedence } \\
\text { relations }\end{array}$ & \\
\hline $\begin{array}{l}\text { Özdamar and } \\
\text { Alanya [25] }\end{array}$ & Fuzzy & $\checkmark$ & - & - & - & $\checkmark$ & Heuristic scheduling algorithm \\
\hline Liu et al. [28] & Fuzzy & $\checkmark$ & $\checkmark$ & - & $\checkmark$ & - & Genetic local search \\
\hline $\begin{array}{l}\text { Wang and Huang } \\
{[31]}\end{array}$ & Fuzzy & $\checkmark$ & - & - & - & - & $\begin{array}{l}\text { Hybrid genetic algorithm and } \\
\text { fuzzy simulation }\end{array}$ \\
\hline Bhaskar et al. [30] & Fuzzy & $\checkmark$ & - & - & - & - & Non-recursive heuristic method \\
\hline $\begin{array}{l}\text { Atli and Kahraman } \\
\text { [3] }\end{array}$ & Fuzzy & $\checkmark$ & - & - & $\checkmark$ & - & $\begin{array}{c}\text { Extended fuzzy CPM \& Taboo } \\
\text { search algorithm }\end{array}$ \\
\hline Kaveh et al. [32] & Fuzzy & $\checkmark$ & - & - & - & - & $\begin{array}{l}\text { CSS and CBO metaheuristic } \\
\text { algorithms }\end{array}$ \\
\hline $\begin{array}{l}\text { Long and Ohsato } \\
\text { [29] }\end{array}$ & Fuzzy & $\checkmark$ & - & - & - & - & Fuzzy critical chain method \\
\hline $\begin{array}{l}\text { Masmoudi and } \\
\text { Hait [36] }\end{array}$ & Fuzzy & $\checkmark$ & - & - & $\checkmark$ & - & $\begin{array}{l}\text { A greedy algorithm based on } \\
\text { parallel SGS }\end{array}$ \\
\hline Yousefli [39] & Fuzzy & $\checkmark$ & $\checkmark$ & $\checkmark$ & $\checkmark$ & - & Fuzzy ACO algorithm \\
\hline $\begin{array}{c}\text { Knyazeva et al. } \\
{[38]}\end{array}$ & Fuzzy & $\checkmark$ & - & - & $\checkmark$ & - & $\begin{array}{c}\text { Combined fuzzy and qualitative } \\
\text { possibility approaches }\end{array}$ \\
\hline Wang [35] & Fuzzy & $\checkmark$ & - & - & $\checkmark$ & - & Genetic algorithm \\
\hline Creemers [17] & Stochastic & $\checkmark$ & - & - & - & - & $\begin{array}{l}\text { Stochastic dynamic } \\
\text { programming }\end{array}$ \\
\hline $\mathrm{Li}$ and Womer [12] & Stochastic & $\checkmark$ & - & - & - & - & $\begin{array}{l}\text { Approximate dynamic } \\
\text { programming }\end{array}$ \\
\hline Chand et al. [21] & Stochastic & $\checkmark$ & $\checkmark$ & - & - & - & $\begin{array}{l}\text { Robust optimization with } \\
\text { evolutionary algorithm }\end{array}$ \\
\hline Perez [13] & Stochastic & $\checkmark$ & - & - & - & - & Simulation-based optimization \\
\hline Tseng and Ko [16] & Stochastic & $\checkmark$ & - & - & - & - & $\begin{array}{l}\text { Scenario-based approach with } \\
\text { utility-entropy decision model }\end{array}$ \\
\hline Artigues et al. [11] & Stochastic & $\checkmark$ & - & - & - & - & $\begin{array}{l}\text { Robust optimization with a } \\
\text { scenario-relaxation algorithm }\end{array}$ \\
\hline Wang et al. [15] & Stochastic & $\checkmark$ & - & - & - & - & $\begin{array}{l}\text { Hybrid GA and an uncertain } \\
\text { serial SGS }\end{array}$ \\
\hline Uysal et al. [22] & Stochastic & - & - & $\checkmark$ & - & - & $\begin{array}{l}\text { Chance constraint, piecewise } \\
\text { linear MIP model }\end{array}$ \\
\hline Rostami et al. [2] & Stochastic & $\checkmark$ & - & - & - & - & $\begin{array}{c}\text { Two-phase local search based } \\
\text { on GRASP \& GA }\end{array}$ \\
\hline Bruni et al. [19] & Stochastic & $\checkmark$ & - & - & - & - & $\begin{array}{l}\text { Benders' decomposition } \\
\text { algorithm }\end{array}$ \\
\hline $\begin{array}{c}\text { Chakrabortty et al. } \\
{[18]}\end{array}$ & Stochastic & $\checkmark$ & - & - & - & - & Robust optimization \\
\hline $\mathrm{Xu}$ and Zhang [43] & Fuzzy random & $\checkmark$ & - & $\checkmark$ & - & - & $\begin{array}{l}\text { Hybrid genetic algorithm with } \\
\text { fuzzy logic controller }\end{array}$ \\
\hline Gang et al. [44] & Fuzzy random & $\checkmark$ & - & - & - & - & $\begin{array}{c}\text { Fuzzy-random simulation } \\
\text { based PSO and GA }\end{array}$ \\
\hline Zhang [45] & Fuzzy random & $\checkmark$ & $\checkmark$ & - & - & - & $\begin{array}{c}\text { Bi-level multiple objective PSO } \\
\text { algorithm }\end{array}$ \\
\hline $\mathrm{Xu}$ and Feng [46] & Fuzzy random & $\checkmark$ & - & $\checkmark$ & - & - & $\begin{array}{l}\text { Combinatorial-priority based } \\
\text { hybrid PSO algorithm }\end{array}$ \\
\hline $\begin{array}{c}\text { Nematian et al. } \\
{[40]}\end{array}$ & Fuzzy random & $\checkmark$ & - & - & $\checkmark$ & - & $\begin{array}{l}\text { MIP based linear } \\
\text { transformation }\end{array}$ \\
\hline $\begin{array}{l}\text { Chen and Zhang } \\
\text { [47] }\end{array}$ & Fuzzy random & $\checkmark$ & - & $\checkmark$ & - & - & Robust optimization \\
\hline The present paper & Interval & $\checkmark$ & $\checkmark$ & $\checkmark$ & $\checkmark$ & - & $\begin{array}{l}\text { Interval programming based } \\
\text { transformation approach }\end{array}$ \\
\hline
\end{tabular}

Definition 4 The mean or midpoint should be a finite element of an interval number and it can be defined by $m\left(A^{ \pm}\right)=$ $\left(A^{-}+A^{+}\right) / 2$. Hereafter, the midpoint of an interval number represents its real isomorphic copy [53],[54].

Definition 5 The half-width of an interval number $A^{ \pm}=$ $\left[A^{-}, A^{+}\right]$can be expressed as: $w\left(A^{ \pm}\right)=\left(A^{+}-A^{-}\right) / 2,[51]$.

Definition 6 For any two interval numbers $A^{ \pm}=\left[A^{-}, A^{+}\right]$and $B^{ \pm}=\left[B^{-}, B^{+}\right]$, a strict partial order on the set of real interval numbers $[\mathbb{R}]$ with respect to the inequality $<$ is defined as [51]:

$$
\left[A^{-}, A^{+}\right]<\left[B^{-}, B^{+}\right] \Leftrightarrow A^{+}<B^{-}
$$

Actually, this order relation can only be used if the given interval numbers do not intersect. In other words, this relation cannot explain ranking between two overlapping intervals [54].

Definition 7 For comparison of two overlapping interval numbers, an acceptability index based on the value judgment $\mathcal{A}_{\odot}$ was proposed by [54],[55] as in Equation (8): 


$$
\mathcal{A}_{\odot}\left(A^{ \pm}, B^{ \pm}\right)=\frac{m\left(B^{ \pm}\right)-m\left(A^{ \pm}\right)}{w\left(B^{ \pm}\right)+w\left(A^{ \pm}\right)}
$$

Actually, this index may be interpreted as the grade of acceptability of the first interval to be inferior to the second one. If $\mathcal{A}_{\odot}\left(A^{ \pm}, B^{ \pm}\right)=0$, then the statement ' $A^{ \pm}$is inferior to $B^{ \pm \prime}$ cannot be accepted. If $0<\mathcal{A}_{\odot}\left(A^{ \pm}, B^{ \pm}\right)<1$, then decision maker may accept this statement with different degrees of satisfaction ranging from zero to one. If $\mathcal{A}_{\odot}\left(A^{ \pm}, B^{ \pm}\right) \geq 1$, then the decision maker completely satisfied that $B^{ \pm}$is superior to $A^{ \pm}$.

Comment 1 Several ordinary principles for operations on real numbers $\mathbb{R}$ are not valid for interval arithmetic [7],[8],[56] as followings where $A^{ \pm}=B^{ \pm}=[3,5] ; A^{ \pm}-A^{ \pm}=[-2,2] \neq 0$ or if $A^{ \pm}+B^{ \pm}=C^{ \pm}=[6,10]$, then $B^{ \pm} \neq C^{ \pm}-A^{ \pm}=[1,7]$.

Alternatively, if $A^{ \pm} \times B^{ \pm}=C^{ \pm}=[9,25]$, then $B^{ \pm} \neq C^{ \pm} \div$ $A^{ \pm}=[1.8,8.33]$. Similar to the standard fuzzy arithmetic, addition/subtraction and multiplication/division operations are not multiplicative inverse for interval numbers. Therefore, previously formulated interval arithmetic operations may cause some doubtful results for many realworld applications, especially in project scheduling. For instance, after resource allocation to the project activities, remaining capacity of a resource may be negative. In other words, resource capacity may be inadequate because of the negative element of its interval-valued remaining capacity. Another example can be given for calculation of starting time of an activity that may also be negative due to the interval subtraction operation. For these reasons, interval arithmetic operations should be performed with requisite constraints or additional information as in the constrained fuzzy arithmetic concept which was first introduced by [57]-[59].

Remark 1 Based on constrained interval arithmetic [57]-[61], crisp equality and inequality relations may be defined between the base variables of two interval numbers for risk-aversion. Equation (9) and (10) denoted interval subtraction operation with crisp equality and inequality constraints, respectively.

$$
\begin{gathered}
\left(A^{ \pm}-B^{ \pm}\right)_{a==b}=\left[A^{-}-B^{-}, A^{+}-B^{+}\right] \\
\left(B^{ \pm}-A^{ \pm}\right)_{a \leq b}=\left\{\begin{array}{c}
{\left[B^{-}-A^{+}, B^{+}-A^{-}\right] \text {if } A^{+} \leq B^{-}} \\
{\left[0, B^{+}-A^{-}\right] \text {otherwise }}
\end{array}\right\}
\end{gathered}
$$

where a and $\mathrm{b}$ are base variables of interval numbers, $A^{ \pm}$and $B^{ \pm}$. In detail, each interval number can be characterized in terms of a base variable whose actual value is in the set of real numbers $\mathbb{R}$. This actual value of the base variable can be approximated by an interval number [7],[57].

Remark 2 In some cases, base variables of interval numbers may be constrained in an uncertain way such as "approximately equal". In fact, there may be an uncertain equality relation between the base variables of interval numbers. This uncertain equality relation can be used in case of risk-seeking [8],[58]. The interval subtraction operation can be rewritten as in Equation (11) under this uncertain equality relation.

$$
\left(A^{ \pm}-B^{ \pm}\right)_{a \approx b}=\left[A^{-}-B^{-}-\Delta \sqrt{2}, A^{+}-B^{+}+\Delta \sqrt{2}\right]
$$

where $\Delta$ is an auxiliary parameter taking a positive real number. The value of this parameter is selected in each context with the purpose of providing the uncertain equality relation a satisfactory representation of the linguistic term "approximately equal". Actually, this auxiliary parameter reflects the project manager's attitude toward risk in the proposed transformation method.

Remark 3 Depending upon the crisp inequality or uncertain equality relations between base variables of interval numbers, constraints in an interval program can be transformed into the crisp equivalent form. Equations (12)-(13) demonstrated the transformation of an interval linear programming constraints for a risk-averse and risk-seeking person, respectively [7].

$$
\begin{gathered}
A^{ \pm} \leq B^{ \pm} \Leftrightarrow\left(B^{ \pm}-A^{ \pm}\right)_{a \leq b} \geq 0 \Leftrightarrow B^{-}-A^{+} \geq 0 \\
A^{ \pm} \leq B^{ \pm} \Leftrightarrow\left(B^{ \pm}-A^{ \pm}\right)_{a \approx b} \geq \pm \Delta \sqrt{2} w\left(B^{ \pm}\right)
\end{gathered}
$$

\section{Formulation of fully uncertain RCPSP}

The fully uncertain RCPSP can be briefly described as follows: We considered a single project consisting of $j=1,2, \ldots, J$ activities which are defined in an activity-on-node (AON) network and have uncertain durations. Therefore, early-late start-finish times of the activities cannot be known precisely. The activities 0 and $J+1$ are the dummy ones that identify source and sink activities and do not take any durations. Due to the technological requirements, there are precedence relations: activity $j$ must not start before each of its predecessors $P_{j}$ are completed [32],[37]. A set $R=\{1,2, \ldots, r\}$ of resources are required for the project to execute. Each resource has a limited uncertain capacity in each time period and activities needed an uncertain amount of resource $r$ during its execution. The AON project network is supposed to be acyclic and an activity cannot be interrupted once started [12]. At this point, let us introduce required notation, parameters and decision variables.

$J \quad$ : Set of project activities to be scheduled,

$T$ : Duration of project without any resource constraint, sum of the interval-valued activity durations,

$R \quad$ : Set of renewable or non-renewable project resources,

$P_{j} \quad: \quad$ Set of activities that immediately completed before $j^{\text {th }}$ activity,

$S_{j} \quad: \quad$ Set of immediate successors of the $j^{\text {th }}$ activity,

$E F T_{j}^{ \pm}:$uncertain time interval for the earliest finish time of $j^{\text {th }}$ activity,

$L F T_{j}^{ \pm} \quad: \quad$ uncertain time interval for the latest finish time of $j^{\text {th }}$ activity,

$d_{j}^{ \pm} \quad: \quad$ uncertain duration of $j^{\text {th }}$ activity,

$k_{j r}^{ \pm} \quad$ : uncertain amount of resource $r$ demanded by $j^{\text {th }}$ activity,

$K r^{ \pm} \quad$ : maximum amount of available resource $r$ in each time period,

$t^{ \pm} \quad$ : current time interval at which the allocation of resources to an activity is considered,

$x_{j t^{ \pm}}:\left\{\begin{array}{l}1 \\ 0\end{array}\right.$ If activity $j$ finished in the time interval $t^{ \pm}$or otherwise.

In addition to these uncertain parameters such as the activity durations, resource capacities and resource requirements of the activities, all of the time indexes for decision variables, i.e., completion times of the activities are also considered as uncertain variables in the proposed interval programming model. In detail, the basic discrete-time binary integer mathematical formulation of RCPSP which was first presented by Pritsker et al. [62] can be modified under interval uncertainty as follows: 


$$
\operatorname{Min} Z^{ \pm}=\sum_{j}^{J} \sum_{t^{ \pm} \in E F T_{j}^{ \pm}}^{L F T_{j}^{ \pm}} t^{ \pm} \cdot x_{j t^{ \pm}} \text {or } \sum_{t^{ \pm} \in E F T_{j}^{ \pm}}^{L F T_{j}^{ \pm}} t^{ \pm} \cdot x_{J t^{ \pm}}
$$

Subject to;

$$
\begin{gathered}
\sum_{t^{ \pm} \in E F T_{j}^{ \pm}}^{L F T_{j}^{ \pm}} x_{j t^{ \pm}}=1 \quad \forall j \in J \\
\sum_{t^{ \pm} \in E F T_{i}^{ \pm}}^{L F T_{i}^{ \pm}} t^{ \pm} \cdot x_{i t^{ \pm}} \lesssim \sum_{t^{ \pm} \in E F T_{j}^{ \pm}}^{L F T_{j}^{ \pm}}\left(t^{ \pm}-d_{j}^{ \pm}\right) \cdot x_{j t^{ \pm}} \forall j \in J, \forall i \in P_{j} \\
\sum_{j}^{J} k_{j r}^{ \pm} \cdot \sum_{\tau^{ \pm} \in t^{ \pm}}^{t^{ \pm}+d_{j}^{ \pm}-1} x_{j \tau^{ \pm}} \lesssim K r^{ \pm} \quad \forall r \in R \text { and } \forall t^{ \pm} \in T \\
x_{j t^{ \pm}} \in\{0,1\} \quad \forall j \in J \text { and } \forall t^{ \pm} \in T
\end{gathered}
$$

The objective function given by Equation (14) aims to minimize makespan or total project time which is the summation of the completion times of all activities. Alternatively, it can be defined as the minimum completion time of the last or ending activity. According to Equation (15), only one completion time interval can be assigned to each activity, ranging between its earliest and latest finishing time intervals. Equation (16) displays precedence relations among the activities. It ensures that an activity cannot begin before completion of its preceding activity. In deterministic environments, completion time of an activity cannot exceed the starting time of its successor. On the other hand, completion time interval of an activity may overlap with the starting time interval of its successor under fully uncertain environments. For this reason, this constraint can be relaxed by performing the interval subtraction operation with the aid of an additional information based on the project manager's risk attitude. Equation (17) is the constraint on the uncertain resource availability at each time period. While realizing the project scheduling process, resource capacities may be inadequate due to the negative lower bounds of the interval-valued remaining capacities which are resulted from interval subtraction operation. This also causes risky solutions to the project manager. In fact, remaining resource capacities should be positive interval numbers for obtaining risk-free solutions. In Equation (18), completion time intervals of the activities are defined as binary variables. Constraints (15) and (18) also impose non-preemption of the activities.

In order to compute the time intervals for the earliest and latest finish times of the activities, traditional forward and backward pass calculations are reformulated as in Equations (19)-(22) based on the interval arithmetic operations and comparison of interval numbers that are given in the previous section.

$$
\begin{gathered}
E S T_{j}^{ \pm}=\begin{array}{c}
\operatorname{Max}\left\{E F T_{i}^{ \pm}\right\} \\
i \in P_{j}
\end{array} \\
E F T_{j}^{ \pm}=E S T_{j}^{ \pm}+d_{j}^{ \pm} \\
L F T_{j}^{ \pm}=\begin{array}{c}
\operatorname{Min}\left\{L S T_{i}^{ \pm}\right\} \\
i \in S_{j}
\end{array}
\end{gathered}
$$

$$
L S T_{j}^{ \pm}=L F T_{j}^{ \pm}-d_{j}^{ \pm}
$$

In detail, interval addition and subtraction operations are performed in Equations (20) and (22), respectively. Additionally, maximum early finishing time interval of the immediate predecessors should be determined in the forward pass. In a similar way, minimum late starting time interval of the immediate successors should be found in the backward pass. These max/min operators require the comparison of the interval numbers. To do this, a strict partial order [51] can be employed if the time intervals do not intersect each other. Otherwise, acceptability index of [54]-[55] can be applied to rank the overlapping time intervals. Finally, total number of discrete-time periods, $T$ can be determined as in Equation (23) to calculate the latest finishing time intervals of the activities.

$$
t^{ \pm} \in T \text { or }[\underline{t}, \bar{t}] \in T=\max \left(\sum_{j}^{J}\left[\underline{d_{j}}, \overline{d_{j}}\right]\right)
$$

In Equation (23), project duration without any resource constraint is calculated by summation of the interval-valued activity durations. This duration will also be utilized as the total number of planning periods in the proposed transformation approach. In the light of this information, interval programming model given in Equations (14)-(18) can be rewritten as follows:

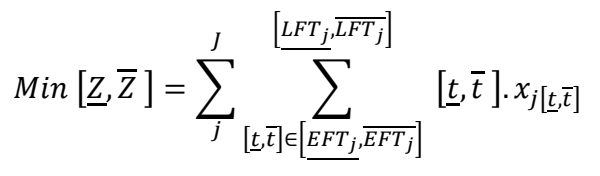

Subject to;

$$
\begin{aligned}
& \sum_{[\underline{t}, \bar{t}] \in\left[\underline{\left.E F T_{j}, \overline{E F T_{j}}\right]}\right.}^{\left[L F T_{j}, \overline{L F T_{j}}\right]} x_{j[\underline{t}, \bar{t}]}=1 \quad \forall j \in J
\end{aligned}
$$

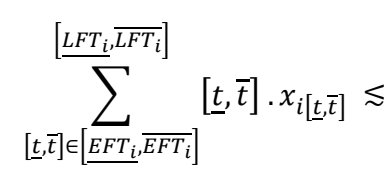

$$
\begin{aligned}
& \sum_{[\underline{t}, \bar{t}] \in\left[\underline{\left.E F T_{j}, \overline{E F T_{j}}\right]}\right.}^{\left[L E T_{j}, \overline{L F T} T_{j}\right]}\left([\underline{t}, \bar{t}]-\left[\underline{d_{j}}, \overline{d_{j}}\right]\right) \cdot x_{j[\underline{t}, \bar{t}]} \quad \forall j \in J, \forall i \in P_{j} \\
& \sum_{j}^{J}\left[\underline{k_{j r}}, \overline{k_{j r}}\right] \cdot \sum_{[\underline{\tau}, \bar{\tau}] \in[\underline{t}, \bar{t}]}^{\left[\underline{t}+\underline{d_{j}}-1, \bar{t}+\overline{d_{j}}-1\right]} x_{j[\underline{\tau}, \bar{\tau}]} \lesssim\left[\underline{K_{r}}, \overline{K_{r}}\right] \\
& \forall r \in R, \quad \forall t^{ \pm}=\{[\underline{t}, \bar{t}] \mid \underline{t}=\bar{t} \in T\} \\
& x_{j[\underline{t}, \bar{t}]} \in\{0,1\} \quad \forall j \in J, \quad \forall t^{ \pm}=\{[\underline{t}, \bar{t}] \mid \underline{t} \leq \bar{t} \in T\}
\end{aligned}
$$

\subsection{The proposed transformation approach}

In this section, the proposed interval programming model given by Equations (24)-(28) is converted into the crisp equivalent form by considering the project manager's attitude toward risk. The proposed transformation approach mainly depends on interval programming, interval ranking and interval arithmetic 
operations. Furthermore, while performing the interval arithmetic operations, especially the subtraction operations, supplementary information obtained from the project manager is also taken into account by some additional constraints. The objective function of the transformed model is to minimize the summation of the midpoints of interval-valued completion times of all activities as formulated in Equation (29).

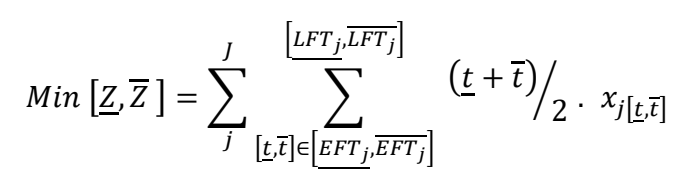

The constraint (25) can be converted into the crisp equivalent form as in Equation (30). This constraint guarantees that an activity can be completed within only one time interval that must be lie between its earliest/latest finishing time intervals.

$$
\sum_{\underline{t} \in \underline{E F T_{j}}}^{\overline{L F T_{j}}} \sum_{\bar{t} \in E F T_{j}}^{\& \bar{t} \geq \underline{t}} x_{j \underline{t} \bar{t}}=1 \quad \forall j \in J
$$

One of the risky situation in project scheduling under uncertainty is that starting time interval of an activity may have a negative lower bound due to the standard interval subtraction operation. It was also mentioned by Atli and Kahraman [3] that fuzzy subtraction operation for computing fuzzy latest starting times may cause unreasonable negative values of times. For this reason, they recommended development of a project scheduling risk index to support the project planners for evaluating the project's scheduling risks. In this paper, in order to overcome this problematic issue, interval subtraction operations are performed under an additional information obtained from the project manager. Indeed, this information reflects the project manager's risk attitude. To do this, a requisite constraint in Equation (31) is incorporated into the proposed interval programming model.

$$
\sum_{[\underline{t}, \bar{t}] \in\left[\underline{\left.E F T_{j}, \overline{E F T_{j}}\right]}\right.}^{\left[\underline{L E T_{j}}, \overline{L F T_{j}}\right]}\left[x_{j[\underline{t}, \bar{t}]} \gtrsim\left[\underline{d_{j}}, \overline{d_{j}}\right] \quad \forall j \in J\right.
$$

Constraint (31) ensures that the completion time interval of an activity should be greater than its interval-valued duration. This also provides positive starting time intervals for the activities. In a risk-averse environment, lower bound of an activity's completion time interval cannot be less than the upper bound of its duration. From the perspective of project manager's risk attitude, constraint (31) can be converted into the crisp equivalent form as in Equations (32) and (33). In fact, these constraints are formulated based on the uncertain equality relations between base variables of interval numbers as previously mentioned in Remark 3.

$$
\begin{aligned}
& \sum_{\underline{t} \in \underline{E F T_{j}}}^{\overline{L F T_{j}}} \sum_{\bar{t} \in E F T_{j}}^{\overline{L F T_{j}}} \underline{t} \cdot x_{j} \underline{t} \bar{t}-\bar{t} \bar{d}_{j} \geq \\
& -\theta \cdot \sqrt{2}\left(\frac{\sum_{\underline{t} \in \underline{E F T_{j}}}^{\overline{L F T_{j}}} \sum_{\overline{t \in E F T_{j}} \& \bar{t} \geq \underline{t}}^{\overline{L F T_{j}}} \overline{\underline{t} \cdot x_{j} \underline{t} \bar{t}-\underline{t} \cdot x_{j} \underline{t} \bar{t}}}{2}\right) \forall j \in J
\end{aligned}
$$

$$
\begin{aligned}
& \sum_{\underline{t} \in \underline{E F T_{j}}}^{\overline{L F T_{j}}} \sum_{\bar{t} \in \underline{E F T_{j}} \& \bar{t} \geq \underline{t}}^{\overline{L F T_{j}}} \bar{t} \cdot x_{j} \underline{t} \bar{t}-\underline{d_{j}} \geq
\end{aligned}
$$

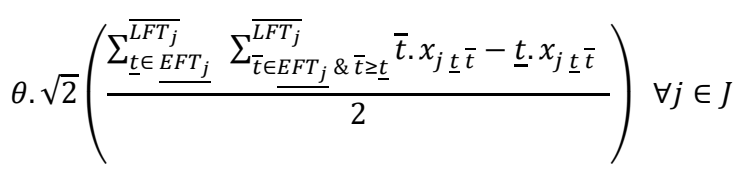

When the risk parameter $(\theta)$ of the project manager is equal to " 0 ", risk-free solutions which always have positive starting time intervals can be provided. However, when the value of this risk parameter is set to $\sqrt{2}$, one can obtain risky solutions including negative starting time intervals. These additional constraints can be formulated as in Equations (34)-(35) for a risk-averse project manager. According to the values of this risk parameter $0 \leq \theta \leq \sqrt{2}$, the proposed approach may produce various crisp or interval-valued solutions under consideration of different risk attitudes.

$$
\begin{aligned}
& \sum_{\underline{t} \in \underline{E F T_{j}}}^{\overline{L F T_{j}}} \sum_{\bar{t} \in \underline{E F T_{j}} \& \bar{t} \geq \underline{t}}^{\overline{L F T_{j}}} \underline{t} x_{j \underline{t} \bar{t}}-\overline{d_{j}} \geq 0 \quad \forall j \in J
\end{aligned}
$$

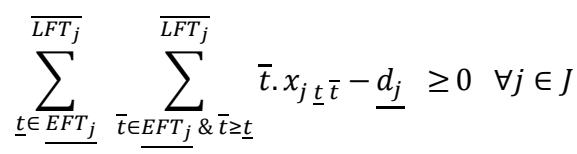

The precedence relations in Equation (26) can be transformed into the crisp equivalent form as in Equations (36)-(37). In these constraints, $\alpha$ also denotes another risk parameter. In a risk-averse environment, completion time intervals of the successive activities never overlap with each other.

$$
\begin{aligned}
& \sum_{\underline{t} \in \underline{E F T_{i}}}^{\overline{L F T_{i}}} \sum_{\overline{t \in E F T_{i}} \& \bar{t} \geq \underline{t}}^{\overline{L F T_{i}}} \underline{t} \cdot x_{i \underline{t} \bar{t}} \leq \\
& \left.\sum_{\underline{t} \in E F T_{j}}^{\overline{L F T_{j}}} \sum_{\bar{t} \in E F T_{j}}^{\overline{L F T_{j}}}\left[\alpha \cdot \underline{t} \underline{t} \underline{t}-\underline{d_{j}}\right)+(1-\alpha) \cdot\left(\underline{t}-\overline{d_{j}}\right)\right] \cdot x_{j \underline{t} \underline{t}} \\
& \forall j \in J, \forall i \in P_{j} \\
& \sum_{\underline{t} \in \underline{E F T_{i}}}^{\overline{L F T_{i}}} \sum_{\bar{t} \in E F T_{i} \& \bar{t} \geq \underline{t}}^{\overline{L F T_{i}}} \bar{t} \cdot x_{i \underline{t} \bar{t}} \leq \\
& \sum_{\underline{t} \in E F T_{j}}^{\overline{L F T_{j}}} \sum_{\bar{t} \in E F T_{j}} \& \bar{t} \geq \underline{t} \underline{\overline{L F T_{j}}}\left[\alpha \cdot\left(\bar{t}-\overline{d_{j}}\right)+(1-\alpha) \cdot\left(\bar{t}-\underline{d_{j}}\right)\right] \cdot x_{j \underline{t}} \bar{t} \\
& \forall j \in J, \forall i \in P_{j}
\end{aligned}
$$

Knyazeva et al. [38] also highlighted that fuzzy starting times may overlap with fuzzy finishing times of its predecessors and thus, preceding activities may not be fully completed because of the resource unavailability. This causes resource unavailability risk and the risk of not meeting the strict precedence relations. In this paper, for a risk-averse project manager, standard interval subtraction operations are performed in the precedence relations. This provides no intersection between the completion time intervals. In other words, lower bound of the completion time interval of the successor activity will be equal or greater than the upper bound of the completion time 
interval of its preceding activity. This also guarantees no overlap between the completion time intervals. On the other hand, although there is a precedence relation between any two activities, their completion time intervals may intersect each other. However, despite of this intersection, completion time interval of an activity should be superior when compared to the completion time interval of its predecessors. To satisfy this condition, an interval ranking method can also be utilized. But, this makes the mathematical model of the stated problem highly non-linear as in the study of Yousefli [39]. When the risk parameter $(\alpha)$ of the project manager is equal to " 0 ", risk-free solutions resulting from standard interval arithmetic can be yielded. Otherwise, risky solutions which contain overlaps of the interval numbers are produced when the risk parameter $(\alpha)$ is equal to " 1 ". The resource availability constraint (27) can be transformed into the crisp equivalent form as in Equations (38)-(39). Similar to the Equations (32)-(33), the transformation of the resource availability constraint is carried out under uncertain equality relations between the base variables of interval numbers. In detail, there are two different risky situations related to this constraint. For that reason, two risk parameters $\beta$ and $\Delta$ are defined so as to reflect the project manager's risk attitude.

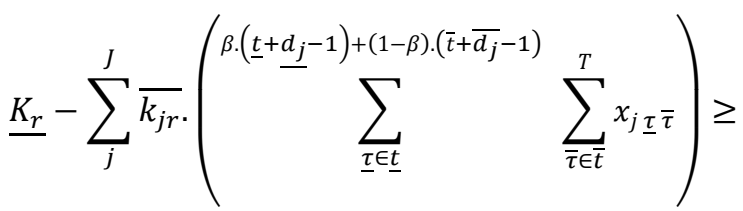

$$
\begin{aligned}
& -\Delta \sqrt{2} \cdot\left(\frac{\overline{K_{r}}-\underline{K_{r}}}{2}\right) \forall r \in R, \forall \underline{t}=\bar{t} \in T
\end{aligned}
$$

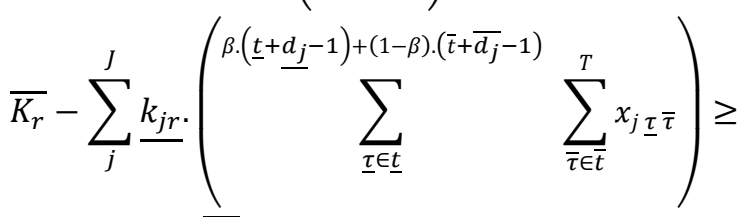

$$
\begin{aligned}
& \Delta \sqrt{2} \cdot\left(\frac{\overline{K_{r}}-\underline{K_{r}}}{2}\right) \forall r \in R, \forall \underline{t}=\bar{t} \in T
\end{aligned}
$$

In detail, $\Delta$ parameter is related to the risk of insufficient project resources. Because, remaining capacities of the resources may have a negative lower bound due to the standard interval subtraction operation. For this reason, interval subtraction operations are performed under the uncertain equality relations. When the value of $\Delta$ is equal to " 0 ", it is guaranteed that remaining capacity of each resource will be a positive interval number. On the contrary, negative remaining resource capacities are allowed in case of $\Delta=\sqrt{2}$. It should be noted here that resource capacities should be sufficient for project execution and do not contain any negative element for a riskaverse project manager. However, remaining resource capacities with a negative lower bound may be acceptable for a risk-seeking project manager because of a better project makespan. Other risky situation is also associated with resource availability instead of insufficient remaining resource capacity. Actually, there is a risk of exceeding the upper bounds of the resource capacities when the time interval is defined as $[\underline{\tau}, \bar{\tau}] \in\left[\underline{t}+d_{j}-1, T\right]$ in constraints (38)-(39). This type of risk can be avoided by defining the time interval as $[\underline{\tau}, \bar{\tau}] \in$ $\left[\bar{t}+\overline{d_{j}}-1, T\right]$. Therefore, when the risk parameter $\beta$ is equal to " 0 ", the proposed approach will provide risk-free solutions for a risk-averse project manager. In the opposite case, risk of exceeding the upper bound of interval-valued resource capacity may be tolerated by a risk-seeking project manager. The risk embedded solutions are generated when this risk parameter $(\beta)$ is taken as "1". In summary, constraints (38)-(39) can be reduced to the following Equations (40)-(41) for a risk-averse project manager.

$$
\begin{aligned}
& \sum_{j}^{J} \overline{k_{j r}} \cdot \sum_{\underline{\tau} \in \underline{t}}^{\bar{t}+\overline{d_{j}}-1} \sum_{\bar{\tau} \in \bar{t}}^{T} x_{j \underline{\tau}} \leq \underline{K_{r}} \quad \forall r \in R, \forall \underline{t}=\bar{t} \in T \\
& \sum_{j}^{J} \underline{k_{j r}} \cdot \sum_{\underline{\tau} \in \underline{t}}^{\bar{t}+\overline{d_{j}}-1} \sum_{\bar{\tau} \in \bar{t}}^{T} x_{j \underline{\tau}} \leq \bar{\tau} \overline{K_{r}} \quad \forall r \in R, \forall \underline{t}=\bar{t} \in T
\end{aligned}
$$

All of these risky situations mentioned here are also illustrated in the next sub-section through a basic numerical example.

Briefly, the main advantages of the proposed transformation approach can be listed as follows. The proposed approach is able to handle fully uncertain RCPSP in which all of the project parameters as well as the project schedules are stated as uncertain parameters and variables. Instead of crisp schedules, interval-valued project schedules can be generated by the proposed approach under fully uncertain environments. By making use of the proposed approach, more applicable, realizable and information efficient project schedules can be obtained according to the project manager's attitude toward risk (Risk-averse, risk-neutral, risk-seeker etc.). The proposed approach can take into account different risky situations in an uncertain RCPSP. In detail, four different types of risky situations are examined. (i) Starting time interval of an activity may have a negative lower bound. (ii) Lower bound of the completion time interval of a successive activity may be less than the upper bound of the completion time interval of its preceding activity (non-satisfaction of the precedence relations among the activities). (iii) The resource capacities may be inadequate while realizing the project activities and so resource demands of the activities may not be fully satisfied. (iv) Finally, total resource consumption of the activities may exceed the upper bound of the resource limit at any given time interval. It should be noted here that in contrast to the highly non-linear models in the literature, after applying the proposed transformation approach, a basic linear integer crispequivalent model which can be easily solved by an optimization software is provided.

\subsection{An illustrative example for risky situations}

In order to illustrate the risky situations in project scheduling under resource constraints, a trivial numerical example consisting of five activities and two types of resources is presented. In Figure 1, AON network diagram of the project is given with interval-valued activity durations. Moreover, resource consumptions and the earliest-latest finishing time intervals of the activities are presented in Table 2. Actually, the earliest and latest finishing time intervals are calculated by making use of Equations (19)-(22) by considering the ranking of interval numbers. The starting time of the project is certain and can be expressed as $t_{0}^{ \pm}=[0,0]$. Capacities of two resources are assumed to be $K_{1}^{ \pm}=[4,9]$ and $K_{2}^{ \pm}=[5,10]$, respectively. 


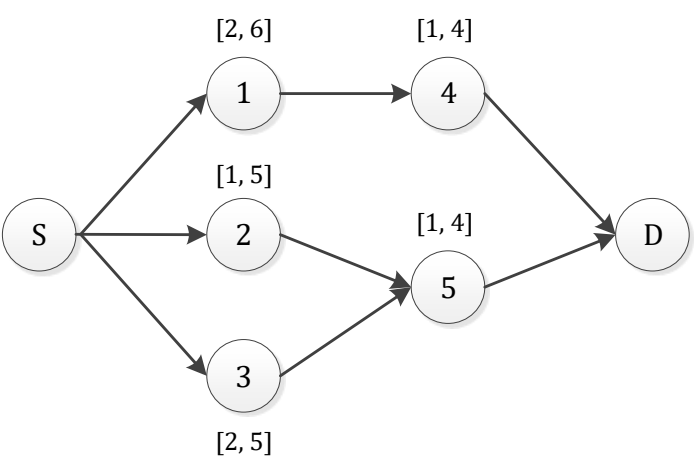

Figure 1: AON project network with uncertain durations.

Table 2: Data on resource consumption \& finish time intervals.

\begin{tabular}{ccc|cc}
\hline \multirow{2}{*}{ Activity } & \multicolumn{2}{c|}{ Resource consumption } & \multicolumn{2}{c}{ Finishing times } \\
\cline { 2 - 5 } & Resource-1 & Resource-2 & Early & Late \\
\hline 1 & {$[1,3]$} & {$[2,4]$} & {$[2,6]$} & {$[20,23]$} \\
2 & {$[1,2]$} & {$[1,2]$} & {$[1,5]$} & {$[20,23]$} \\
3 & {$[2,4]$} & {$[3,5]$} & {$[2,5]$} & {$[20,23]$} \\
4 & {$[1,2]$} & {$[1,2]$} & {$[3,10]$} & {$[24,24]$} \\
5 & {$[1,3]$} & {$[2,4]$} & {$[3,9]$} & {$[24,24]$} \\
\hline
\end{tabular}

When the interval-valued activity durations are summed, it is clear that latest start and finishing times of the dummy activity, $D$ will be equal to 24 . Thus, in the crisp equivalent model, this value is utilized as the total number of discrete-time periods.

As mentioned previously, the first type of risk is that starting time interval of an activity may have a negative lower bound. In order to demonstrate this type of project risk, the crisp equivalent model is solved in case of risk parameter $\theta=\sqrt{2}$. All of the other risk parameters, i.e., $\alpha, \beta, \Delta$ are assumed to be zero. In this case, the completion time interval of activity-1 is obtained as $[2,6]$. When starting time $\left(S T_{j}^{ \pm}\right)$interval of that activity is calculated, it is clearly seen from Equation (42) that it has a negative lower bound. However, activity starting time interval could not be less than $[t, \bar{t}]=[0,0]$ for a risk-averse project manager. In order to prevent this type of risk, interval subtraction operations can be performed under the crisp inequality relation among the base variables of the interval numbers as mentioned in Remark 1-3 and Equations (34)-(35).

$$
S T_{j}^{ \pm}=[\underline{t}, \bar{t}] \cdot x_{j[\underline{t}, \bar{t}]}-\left[\underline{d_{j}}, \overline{d_{j}}\right]=[2,6]-[2,6]=[-4,4]
$$

The second type of risk is that lower bound of the completion time interval of a successive activity may be less than the upper bound of the completion time interval of its preceding activity. In this case, completion time intervals of the consecutive activities may overlap with each other. Actually, this cannot be seen as a strict precedence relation by a risk-averse person. In order to illustrate this type of project risk, the crisp equivalent model is solved under the following conditions: $\alpha=0, \beta=$ $1, \theta=\Delta=\sqrt{2}$. In this case, completion time intervals are obtained as $[3,6]$ and $[7,7]$ for the consecutive activities 1 and 4 , respectively. The provided solutions are also presented in Table 3. It is clear that these completion time intervals do not intersect each other and satisfy a strict precedence relation which is desired by a risk-averse project manager. In the opposite case, completion time intervals are provided as $[3,6]$ and $[4,10]$ for the same activities. This overlap between the interval-valued completion times may be tolerated by a riskseeking project manager. The similar cases are also valid for the activities 2-3 and their successor activity-5. The precedence relation between the activities 1 and 4 can be summarized as in Equation (43).

For $\alpha=0 \Rightarrow[3,6] \leq[7,7] ; \alpha=1 \Rightarrow[3,6] \leq[4,10]$

The third type of risky situation is that the resource capacities may be inadequate while realizing the project. In detail, when resource requirements of the relevant activities are subtracted from the total available resource capacity at a certain time period, the remaining interval-valued resource capacity may have a negative lower bound. Thus, resource demands of the activities may not be fully satisfied. To exemplify this type of project risk, crisp equivalent model is solved under the following conditions: $\alpha=\beta=\theta=0, \Delta=\sqrt{2}$. In this case, crisp completion times are acquired as given in the second column of Table 3 . The provided crisp solution is also depicted in Figure 2 for resource type-1.

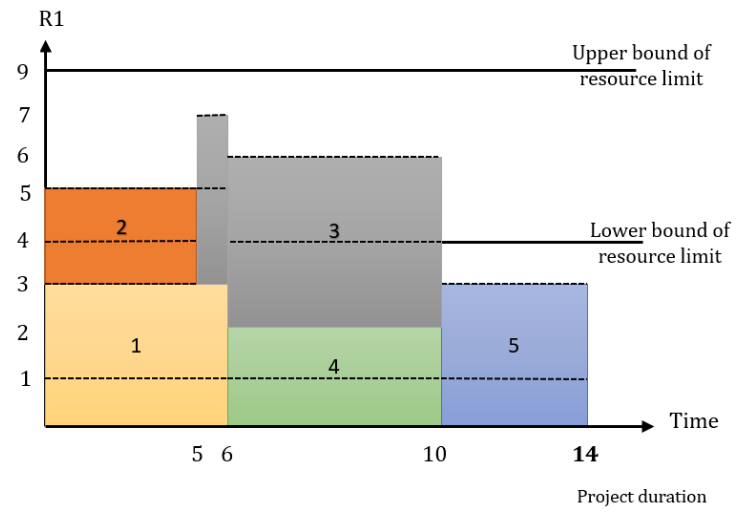

Figure 2: The resource profile with a risky situation.

It is clear in Figure 2 that lower bound of the resource limit will be exceeded by the total resource requirements of the activities. When the remaining capacity of resource type- 1 is computed for the time intervals $[1,5],[5,6]$ and $[6,10]$, it is recognized that there is a risk of insufficient resource capacity. The negative elements of the remaining resource capacity $\left(R C_{i}^{ \pm}\right)$are presented in Equations (44)-(46) for these time intervals.

$$
\begin{gathered}
R C_{1}^{ \pm}=[4,9]-\{[1,3]+[1,2]\}=[-\mathbf{1}, 7] \Longrightarrow[1,5] \\
R C_{1}^{ \pm}=[4,9]-\{[1,3]+[2,4]\}=[-\mathbf{3}, 6] \Longrightarrow[5,6] \\
R C_{1}^{ \pm}=[4,9]-\{[2,4]+[1,2]\}=[-2,6] \Longrightarrow[6,10]
\end{gathered}
$$

In order to generate a risk-free solution demanded by a riskaverse project manager, the crisp equivalent model is resolved under the following condition: $\alpha=\beta=\theta=\Delta=0$. The provided results are depicted in Figure 3.

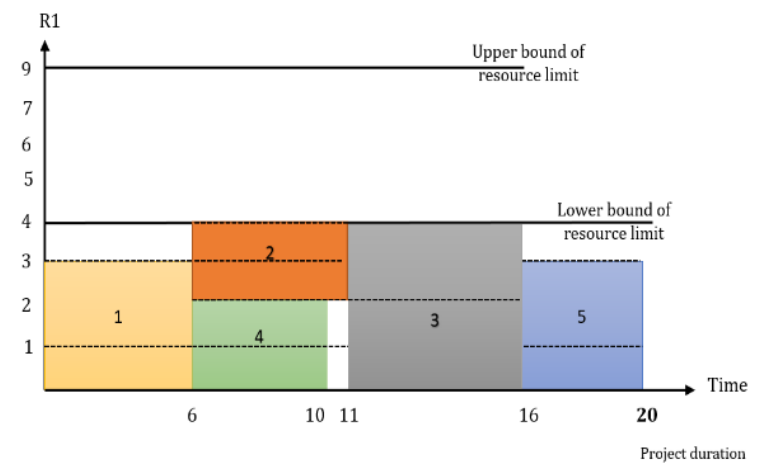

Figure 3: The resource profile without a risky situation. 
Table 3: Completion time intervals of the activities according to different risk attitudes of the project managers.

\begin{tabular}{rccccccc}
\hline Activity & $\boldsymbol{\alpha}=\boldsymbol{\beta}=\boldsymbol{\theta}=\boldsymbol{\Delta}=\mathbf{0}$ & $\begin{array}{c}\boldsymbol{\alpha}=\boldsymbol{\beta}=\boldsymbol{\theta}=\mathbf{0} \\
\boldsymbol{\Delta}=\sqrt{\mathbf{2}}\end{array}$ & $\begin{array}{c}\boldsymbol{\alpha}=\boldsymbol{\theta}=\mathbf{\Delta = \mathbf { 0 }} \\
\boldsymbol{\beta}=\mathbf{1}\end{array}$ & $\begin{array}{c}\boldsymbol{\alpha}=\boldsymbol{\beta}=\mathbf{0} \\
\boldsymbol{\theta}=\boldsymbol{\Delta}=\sqrt{\mathbf{2}}\end{array}$ & $\begin{array}{c}\boldsymbol{\alpha}=\mathbf{1}, \boldsymbol{\beta}=\mathbf{0} \\
\boldsymbol{\theta}=\boldsymbol{\Delta}=\sqrt{\mathbf{2}}\end{array}$ & $\begin{array}{c}\boldsymbol{\alpha}=\mathbf{0}, \boldsymbol{\beta}=\mathbf{1} \\
\boldsymbol{\theta}=\boldsymbol{\Delta}=\sqrt{\mathbf{2}}\end{array}$ & $\begin{array}{c}\boldsymbol{\alpha}=\boldsymbol{\beta}=\mathbf{1} \\
\boldsymbol{\theta}=\boldsymbol{\Delta}=\sqrt{\mathbf{2}}\end{array}$ \\
\hline 1 & {$[6,6]$} & {$[6,6]$} & {$[8,8]$} & {$[2,6]$} & {$[2,6]$} & {$[3,6]$} & {$[3,6]$} \\
2 & {$[11,11]$} & {$[5,5]$} & {$[6,6]$} & {$[1,5]$} & {$[1,5]$} & {$[1,5]$} & {$[1,5]$} \\
3 & {$[16,16]$} & {$[10,10]$} & {$[5,5]$} & {$[6,6]$} & {$[7,7]$} & {$[2,5]$} & {$[2,5]$} \\
4 & {$[10,10]$} & {$[10,10]$} & {$[12,12]$} & {$[6,7]$} & {$[3,10]$} & {$[7,7]$} & {$[4,10]$} \\
5 & {$[20,20]$} & {$[14,14]$} & {$[10,10]$} & {$[10,10]$} & {$[8,11]$} & {$[6,6]$} & {$[3,9]$} \\
\hline
\end{tabular}

Again, crisp solution is produced as presented in the first column of Table 3. But in this case, project makespan increases. According to Equation (47), remaining resource capacity should be a non-negative interval number. Moreover, total resource demands of the activities don't exceed the lower bound of this resource limit.

$$
R C_{1}^{ \pm}=[4,9]-\{[1,2]+[1,2]\}=[0,7] \Rightarrow[6,10]
$$

The last type of project risk is that total resource demands of the activities may exceed the upper bound of the resource limit at any given time interval. In order to illustrate this type of project risk, the risk parameter $(\beta)$ is set to " 1 " where all of the other risk parameters are assumed to be zero. When the crisp equivalent model is solved under this condition, the results are provided as in the third column of Table 3 . The profile of the resource type- 2 is also demonstrated in Figure 4.

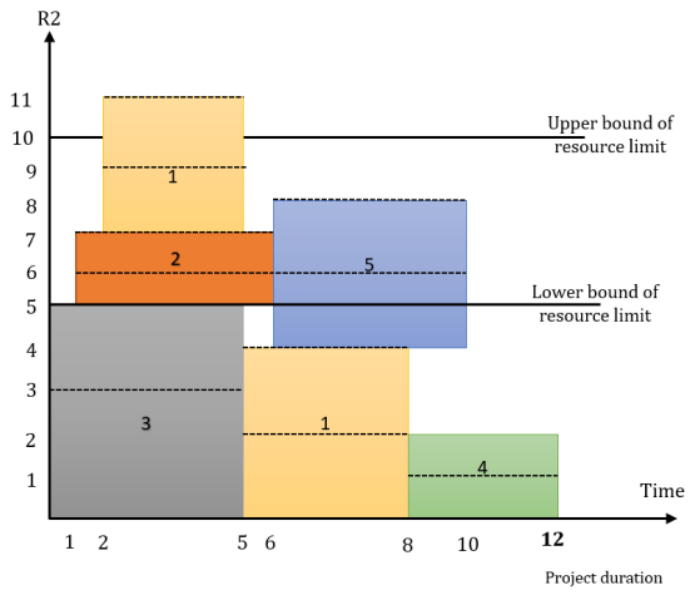

Figure 4: The resource profile with unavailability risk.

According to Figure 4, although the project makespan is relatively shorter when compared to the previous cases (given in Figures 2, 3), the upper bound of resource type- 2 will be exceeded within the time interval [2,5]. This also causes resource unavailability and cannot be accepted by a risk-averse project manager. In this situation, remaining capacity of the resource type- 2 will also be a huge negative interval number as given by Equation (48).

$$
\begin{gathered}
R C_{2}^{ \pm}=[5,10]-\{[2,4]+[1,2]+[3,5]\}=[-6,4] \\
\Longrightarrow[2,5]
\end{gathered}
$$

\section{Application to a tank construction project}

In the scope of project management, project scheduling and selection problems have a wide range of applications from software engineering to monorail transport systems [63],[64]. In order to illustrate usefulness, validity and practicality of the proposed interval programming based transformation approach, a computational study is performed on a real-life case study in an LNG (liquefied natural gas) storage tank project which has been constructed for a petroleum refinery in Saudi Arabia [6],[65],[66]. Similar to the other construction projects, LNG tank construction is subject to considerable uncertainty. Because, considering the uniqueness of that project, it is common that activities are seldom or have never been executed before. Therefore, activities' durations cannot be known precisely in advance. Moreover, as it was also emphasized by Subulan et al. [65] that activity durations in construction projects are generally affected by some external factors such as cultural differences among the workers, climate and safety condition of the project etc. Actually, construction projects can often be delayed by an unexpected weather or disruption of logistics [12]. Similarly, amounts of the available resources can be seen as the other uncertain inputs that may not be known before a construction project realization.

Briefly, in this case study, the activity duration times, resource requirements (Manpower and machinery) and capacities are estimated by the project managers using interval numbers based on their expertise and knowledge. Because, as it was also emphasized by [3]-[5] that it may be impossible to derive the probability distributions of the activity durations and resource requirements explicitly. Because, similar comprehensive construction projects (such an LNG storage tank design) may have not been carried out previously. Therefore, project managers may have not sufficient data at the beginning of the project scheduling phase due to the uniqueness of the project. Moreover, such a human expertise on the project parameters generally involves ambiguous or vague information which cannot be modelled by using stochastic approaches.

It should also be mentioned here that during the project execution, resource capacities, duration times and resource requirements of the activities are generally vague in most of the practical project scheduling cases. Additionally, vagueness of these project parameters may not be described by random variables in most of the cases due to the lack of statistical past data [3]-[5]. Manpower and machinery such as crane or equipment for earth moving, compaction and excavation are the main sources of a construction project. In this paper, the 
manpower and machinery requirements are defined in terms of the number of workers and machine-hours, respectively. Based on these information, we concerned with a fully uncertain LNG tank construction project scheduling under limited resources. Some visual depictions are shown in Figures 5 and 6 for an LNG storage tank design and construction.

The descriptions, durations and resource requirements of the activities in an LNG tank construction project are summarized

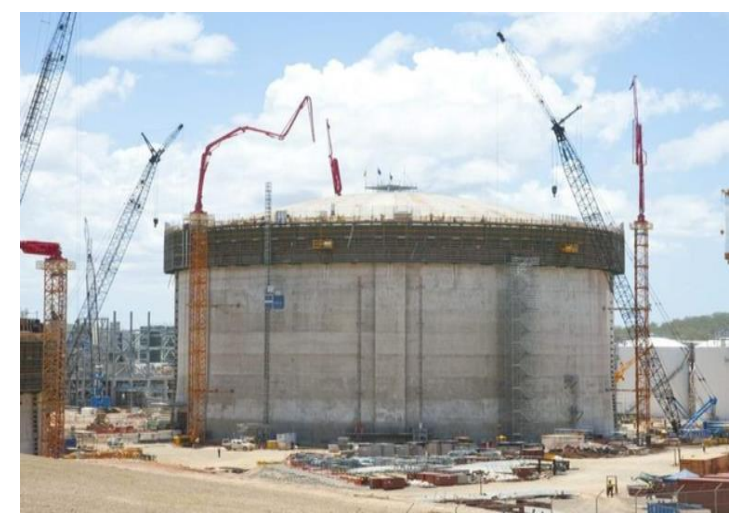

Figure 5: Visualization of an LNG tank construction [67]. in Table 4 with their immediate predecessors and early/late finishing time intervals. The precedence relations among these activities can also be seen from the AON project network shown in Figure 7. The results of the proposed approach with respect to the project managers' risk attitudes are given in Table 5.

While generating these results, LINGO 15.0 optimization software is used on an Intel Core i7 $2.4 \mathrm{GHz}$ IBM PC. Some optimization details are also presented in Table 6.

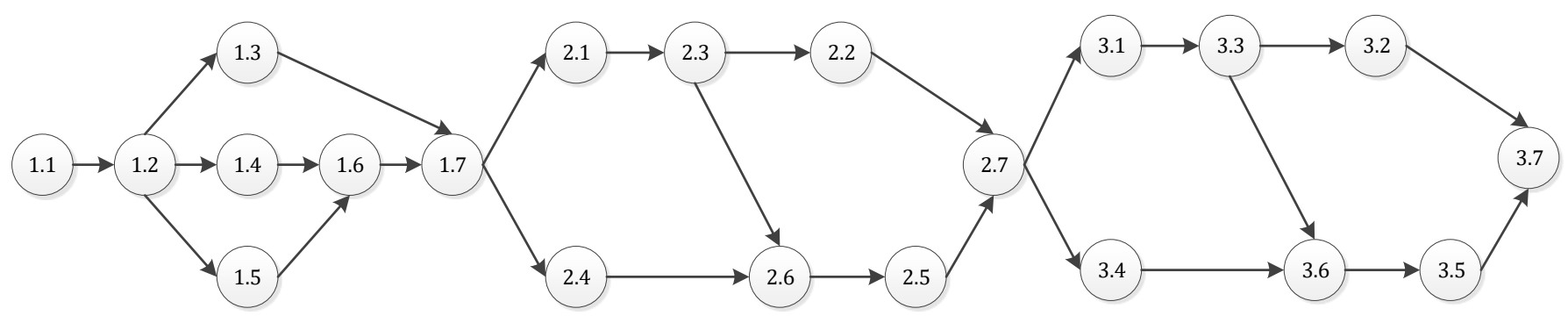

Figure 7: AON network diagram of an LNG storage tank construction project.

Table 4: Activity descriptions and project data in the case study.

\begin{tabular}{|c|c|c|c|c|c|c|}
\hline Activity Description & $\begin{array}{c}\text { Duration } \\
\text { (Days) }\end{array}$ & $\begin{array}{l}\text { Manpower } \\
\text { Req. }\end{array}$ & $\begin{array}{l}\text { Machinery } \\
\text { Req. }\end{array}$ & $\begin{array}{c}\text { Immediate } \\
\text { predecessors }\end{array}$ & $\begin{array}{l}\text { Early Finish } \\
\text { Time (EFT) }\end{array}$ & $\begin{array}{l}\text { Latest Finish } \\
\text { Time (LFT) }\end{array}$ \\
\hline \multicolumn{7}{|c|}{ Foundation Works } \\
\hline 1.1 Sub-base leveling & {$[2,5]$} & {$[5,8]$} & {$[50,60]$} & - & {$[2,5]$} & {$[30,62]$} \\
\hline 1.2 Lean concrete & {$[1,3]$} & {$[2,5]$} & {$[30,40]$} & 1.1 & {$[3,8]$} & {$[33,63]$} \\
\hline 1.3 Formwork to foundation & {$[4,7]$} & {$[2,4]$} & {$[10,15]$} & 1.2 & {$[7,15]$} & {$[51,74]$} \\
\hline 1.4 Rebar installation to foundation & {$[8,12]$} & {$[18,22]$} & {$[20,30]$} & 1.2 & {$[11,20]$} & {$[45,71]$} \\
\hline 1.5 Heating conduit \& inclinometer installation & {$[4,8]$} & {$[3,5]$} & {$[40,50]$} & 1.2 & {$[7,16]$} & {$[45,71]$} \\
\hline 1.6 Anchor plates installation & {$[3,6]$} & {$[3,5]$} & {$[10,15]$} & $1.4 \& 1.5$ & {$[14,26]$} & {$[51,74]$} \\
\hline 1.7 Pouring concrete to foundation & {$[1,2]$} & {$[17,23]$} & {$[60,80]$} & $1.3 \& 1.6$ & {$[15,28]$} & {$[53,75]$} \\
\hline \multicolumn{7}{|c|}{$1^{\text {st }}$ Lift Works } \\
\hline 2.1 Rebar installation to wall & {$[3,6]$} & {$[16,20]$} & {$[30,40]$} & 1.7 & {$[18,34]$} & {$[59,78]$} \\
\hline 2.2 Formwork to inner tank & {$[1,3]$} & {$[17,19]$} & {$[10,15]$} & 2.3 & {$[21,41]$} & {$[80,93]$} \\
\hline 2.3 Embedment installation & {$[2,4]$} & {$[5,7]$} & {$[40,50]$} & 2.1 & {$[20,38]$} & {$[63,80]$} \\
\hline 2.4 Rebar installation of outer wall & {$[1,3]$} & {$[16,20]$} & {$[20,25]$} & 1.7 & {$[16,31]$} & {$[63,80]$} \\
\hline 2.5 Formwork to buttress \& outer tank & {$[9,11]$} & {$[6,10]$} & {$[15,20]$} & 2.6 & {$[33,35]$} & {$[80,93]$} \\
\hline 2.6 Post-tensioning duct installation & {$[4,6]$} & {$[2,4]$} & {$[35,50]$} & $2.3 \& 2.4$ & {$[24,44]$} & {$[69,84]$} \\
\hline 2.7 Pouring concrete & {$[1,2]$} & {$[10,13]$} & {$[50,65]$} & $2.2 \& 2.5$ & {$[34,57]$} & {$[82,94]$} \\
\hline \multicolumn{7}{|c|}{$2^{\text {nd }}$ Lift Works } \\
\hline 3.1 Rebar installation to wall & {$[2,4]$} & {$[16,20]$} & {$[25,30]$} & 2.7 & {$[36,61]$} & {$[86,96]$} \\
\hline 3.2 Formwork to inner tank & {$[1,2]$} & {$[13,16]$} & {$[10,15]$} & 3.3 & {$[39,68]$} & {$[105,106]$} \\
\hline 3.3 Embedment installation & {$[2,5]$} & {$[3,5]$} & {$[40,50]$} & 3.1 & {$[38,66]$} & {$[91,98]$} \\
\hline 3.4 Rebar installation of outer wall & {$[1,2]$} & {$[13,17]$} & {$[20,30]$} & 2.7 & {$[35,59]$} & {$[91,98]$} \\
\hline 3.5 Formwork to buttress \& outer tank & {$[6,10]$} & {$[8,11]$} & {$[15,20]$} & 3.6 & {$[46,80]$} & {$[105,106]$} \\
\hline 3.6 Post-tensioning duct installation \& anchor & {$[2,4]$} & {$[4,6]$} & {$[40,50]$} & $3.3 \& 3.4$ & {$[40,70]$} & {$[95,100]$} \\
\hline 3.7 Pouring concrete & {$[1,2]$} & {$[9,14]$} & {$[60,80]$} & $3.2 \& 3.5$ & {$[47,82]$} & {$[107,107]$} \\
\hline
\end{tabular}


Table 5: Computational results according to different risk attitudes of the project managers.

\begin{tabular}{|c|c|c|c|c|c|c|c|c|c|}
\hline \multirow[t]{2}{*}{ Activity } & \multirow{2}{*}{$\begin{array}{l}\text { Risk- } \\
\text { averse }\end{array}$} & \multicolumn{3}{|c|}{ Partially risk-averse } & \multicolumn{4}{|c|}{ Partially risk-seeker } & \multirow{2}{*}{$\begin{array}{l}\text { Risk- } \\
\text { seeker }\end{array}$} \\
\hline & & $\beta=1$ & $\Delta=\sqrt{2}$ & $\Delta=\theta=\sqrt{2}$ & $\begin{array}{c}\alpha=1, \beta=0 \\
\Delta=\theta=\sqrt{2}\end{array}$ & $\Delta=\theta=0$ & $\Delta=\sqrt{2} / 2$ & $\theta=0$ & \\
\hline 1.1 & {$[5,5]$} & {$[5,5]$} & {$[5,5]$} & {$[2,5]$} & {$[5,5]$} & {$[5,5]$} & {$[2,5]$} & {$[5,5]$} & {$[2,5]$} \\
\hline 1.2 & {$[8,8]$} & {$[8,8]$} & {$[8,8]$} & {$[5,6]$} & {$[8,8]$} & {$[6,8]$} & {$[3,8]$} & {$[6,8]$} & {$[3,8]$} \\
\hline 1.3 & {$[15,15]$} & {$[15,15]$} & {$[23,23]$} & {$[20,20]$} & {$[12,15]$} & {$[10,15]$} & {$[7,15]$} & {$[14,15]$} & {$[7,15]$} \\
\hline 1.4 & {$[28,28]$} & {$[24,24]$} & {$[20,20]$} & {$[17,17]$} & {$[16,20]$} & {$[18,20]$} & {$[15,20]$} & {$[14,20]$} & {$[11,20]$} \\
\hline 1.5 & {$[16,16]$} & {$[16,16]$} & {$[16,16]$} & {$[13,13]$} & {$[16,16]$} & {$[10,16]$} & {$[7,16]$} & {$[10,16]$} & {$[11,16]$} \\
\hline 1.6 & {$[34,34]$} & {$[30,30]$} & {$[26,26]$} & {$[23,23]$} & {$[19,26]$} & {$[21,26]$} & {$[18,26]$} & {$[17,26]$} & {$[14,26]$} \\
\hline 1.7 & {$[36,36]$} & {$[32,32]$} & {$[28,28]$} & {$[25,25]$} & {$[20,28]$} & {$[22,28]$} & {$[19,28]$} & {$[18,28]$} & {$[15,28]$} \\
\hline 2.1 & {$[45,45]$} & {$[38,38]$} & {$[34,34]$} & {$[31,31]$} & {$[26,34]$} & {$[26,34]$} & {$[23,34]$} & {$[21,34]$} & {$[18,34]$} \\
\hline 2.2 & {$[52,52]$} & {$[45,45]$} & {$[41,41]$} & {$[38,38]$} & {$[32,41]$} & {$[29,41]$} & {$[26,41]$} & {$[24,41]$} & {$[21,41]$} \\
\hline 2.3 & {$[49,49]$} & {$[42,42]$} & {$[38,38]$} & {$[35,35]$} & {$[28,38]$} & {$[28,38]$} & {$[25,38]$} & {$[23,38]$} & {$[20,38]$} \\
\hline 2.4 & {$[39,39]$} & {$[35,35]$} & {$[37,37]$} & {$[34,34]$} & {$[29,31]$} & {$[23,31]$} & {$[20,31]$} & {$[22,31]$} & {$[19,31]$} \\
\hline 2.5 & {$[66,66]$} & {$[59,59]$} & {$[55,55]$} & {$[52,52]$} & {$[43,55]$} & {$[41,55]$} & {$[38,55]$} & {$[36,55]$} & {$[33,55]$} \\
\hline 2.6 & {$[55,55]$} & {$[48,48]$} & {$[44,44]$} & {$[41,41]$} & {$[34,44]$} & {$[32,44]$} & {$[29,44]$} & {$[27,44]$} & {$[24,44]$} \\
\hline 2.7 & {$[68,68]$} & {$[61,61]$} & {$[57,57]$} & {$[54,54]$} & {$[44,57]$} & {$[42,57]$} & {$[39,57]$} & {$[37,57]$} & {$[34,5]$} \\
\hline 3.1 & {$[72,72]$} & {$[65,65]$} & {$[61,61]$} & {$[58,58]$} & {$[47,61]$} & {$[44,61]$} & {$[41,61]$} & {$[39,61]$} & {$[36,61]$} \\
\hline 3.2 & {$[79,79]$} & {$[72,72]$} & {$[68,68]$} & {$[65,65]$} & {$[50,68]$} & {$[47,68]$} & {$[44,68]$} & {$[42,68]$} & {$[39,68]$} \\
\hline 3.3 & {$[77,77]$} & {$[70,70]$} & {$[66,66]$} & {$[63,63]$} & {$[49,66]$} & {$[46,66]$} & {$[43,66]$} & {$[41,66]$} & {$[38,66]$} \\
\hline 3.4 & {$[74,74]$} & {$[63,63]$} & {$[63,63]$} & {$[60,60]$} & {$[49,59]$} & {$[45,59]$} & {$[42,59]$} & {$[40,59]$} & {$[37,59]$} \\
\hline 3.5 & {$[91,91]$} & {$[84,84]$} & {$[80,80]$} & {$[77,77]$} & {$\left[\begin{array}{lll}59 & 80\end{array}\right]$} & {$[54,80]$} & {$[51,80]$} & {$[49,80]$} & {$[46,80]$} \\
\hline 3.6 & {$[81,81]$} & {$[74,74]$} & {$[70,70]$} & {$[67,67]$} & {$[53,70]$} & {$[48,70]$} & {$[45,70]$} & {$[43,70]$} & {$[40,70]$} \\
\hline 3.7 & {$[93,93]$} & {$[86,86]$} & {$[82,82]$} & {$[79,79]$} & {$[60,82]$} & {$[55,82]$} & {$[52,82]$} & {$[50,82]$} & {$[47,82]$} \\
\hline
\end{tabular}

Table 6: Some details on optimization results.

\begin{tabular}{cccc}
\hline Optimization Results & Deterministic Case & Proposed Approach \\
\cline { 3 - 4 } & & 310 & Risk-neutral \\
\hline Total variables & 166 & & 42128 \\
Total constraints & PILP & & 119635 \\
Model class & 511 & 1083 & PILP \\
Objective value & - & 83577 & 833 \\
Extended solver steps & 24 & 28221310 & 30703 \\
Total solver iterations & 0.12 & 9255.31 & 31631020 \\
CPU time (Sec) & & 709.5 \\
\hline
\end{tabular}

A risk-averse project manager may not desire to obtain overly imprecise project schedules or high degree of uncertainty on the completion time intervals of the activities. Hence, a riskaverse project manager can obtain crisp and risk-free project schedules as in Tables 3 and 5 . In other words, when the project manager is a risk-averse or partially risk-averse person, the provided solutions are necessarily precise and crisp. However, project makepan or total project time will increase up to 93 days in this situation. When the values of all the risk parameters, i.e., $\alpha, \beta, \theta$ and $\Delta$ are set to zero, the proposed approach may be more suitable for a risk-averse project manager. For this reason, risk attitude of the project manager should be specified before applying the proposed approach. If the project manager is not a risk-averse person, the degree of his/her risk tolerance should be determined carefully for each risky situation. When the risk tolerance of the project manager is increased (or larger values of the risk parameters, $\alpha=\beta=1.0$ and $\theta=\Delta=\sqrt{2}$ ), project makespan will decrease down to the ranges between 47 and 82 days but completion times of the activities will take more imprecise values as it is seen from Table 5 .

Unfortunately, risks for capacity unavailability of the resources and non-satisfaction of the precedence relations among the activities will also increase in these solutions. Since these solutions include high degree of uncertainty, a riskseeking project manager may choose one appropriate crisp schedule among these interval-valued schedules while realizing the project.
In order to analyze the effects of the values of different risk parameters $(\alpha, \beta, \theta$ and $\Delta)$, on the project makespan and provide some managerial insights, a sensitivity analysis is conducted based on a full factorial experimental design. In Table 7, computational results of different factor level combinations on the project makespan are reported. Then, the main effects of different risk parameters on the average project makespan (midpoint of the interval valued project makespan) are obtained as in Figures 8 and 9 from the analysis of full factorial design in Minitab 14. According to Figure 8, $\alpha, \beta$ and $\Delta$ are the most influential risk parameters since they may have a significant impact on the variability of project makespan. In other words, project managers should be careful when dealing with these project risks related to the precedence relations of the activities, capacities and availabilities of the project resources. Furthermore, there may exist some interactions among these project risks as depicted in Figures 9 and 10. According to the interaction graph and normal probability plot of the interaction effects, the interaction among the project risks for the precedence relations and resource capacities may have a moderate impact on the average project makespan. Moreover, it is obviously seen from these figures that risks for resource capacities and availabilities may interact with each other. Therefore, the interaction among the project risks for resource capacities and availabilities should also be taken into account by the project managers carefully in construction industry. 
Table 7: Full factorial experimental design matrix and computational results on the project makespan.

\begin{tabular}{|c|c|c|c|c|c|c|}
\hline Model Run & $\begin{array}{l}\text { Risk parameter } \\
\text { for precedence } \\
\text { relations }(\boldsymbol{\alpha})\end{array}$ & $\begin{array}{l}\text { Risk parameter for } \\
\text { resource capacity } \\
(\boldsymbol{\beta})\end{array}$ & $\begin{array}{l}\text { Risk parameter } \\
\text { for starting time } \\
\qquad(\boldsymbol{\theta})\end{array}$ & $\begin{array}{c}\text { Risk parameter for } \\
\text { resource } \\
\text { availability }(\Delta)\end{array}$ & $\begin{array}{c}\text { Interval Project } \\
\text { Makespan }\end{array}$ & CPU time (sec.) \\
\hline 1 & 0 & 0 & 0 & 0 & {$[93,93]$} & 9255.31 \\
\hline 3 & 0 & 1 & 0 & 0 & {$[86,86]$} & 3867.64 \\
\hline 4 & 1 & 1 & 0 & 0 & {$[55,82]$} & 2476.29 \\
\hline 5 & 0 & 0 & $\sqrt{2}$ & 0 & {$[90,90]$} & 5193.21 \\
\hline 6 & 1 & 0 & $\sqrt{2}$ & 0 & {$[76,82]$} & 1826.35 \\
\hline 7 & 0 & 1 & $\sqrt{2}$ & 0 & {$[83,83]$} & 3665.51 \\
\hline 8 & 1 & 1 & $\sqrt{2}$ & 0 & {$[52,82]$} & 1918.81 \\
\hline 9 & 0 & 0 & 0 & $\sqrt{2}$ & {$[82,82]$} & 40.19 \\
\hline 10 & 1 & 0 & 0 & $\sqrt{2}$ & {$[66,82]$} & 118.24 \\
\hline 11 & 0 & 1 & 0 & $\sqrt{2}$ & {$[82,82]$} & 29.27 \\
\hline 12 & 1 & 1 & 0 & $\sqrt{2}$ & {$[50,82]$} & 37.40 \\
\hline 13 & 0 & 0 & $\sqrt{2}$ & $\sqrt{2}$ & {$[79,79]$} & 41.28 \\
\hline 15 & 0 & 1 & $\sqrt{2}$ & $\sqrt{2}$ & {$[79,79]$} & 31.16 \\
\hline 16 & 1 & 1 & $\sqrt{2}$ & $\sqrt{2}$ & {$[47,82]$} & 31.21 \\
\hline
\end{tabular}

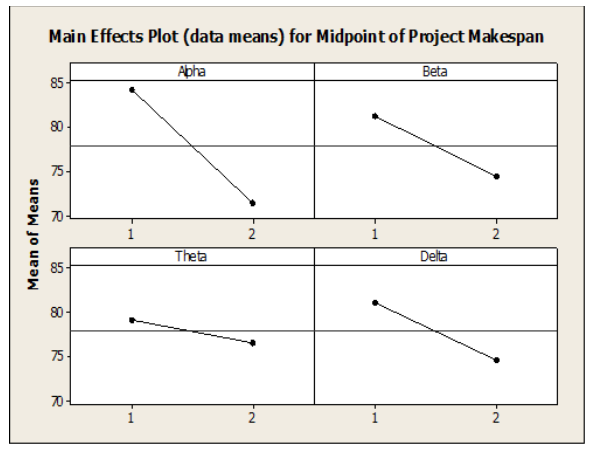

Figure 8: Main effects plots on the average project makespan.

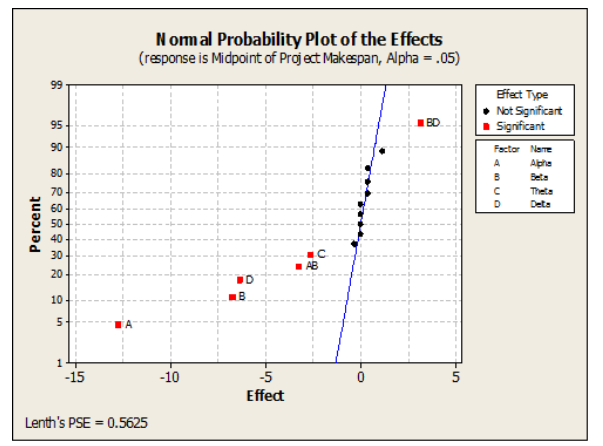

Figure 9: Normal probability plot of the main effects and interaction effects.

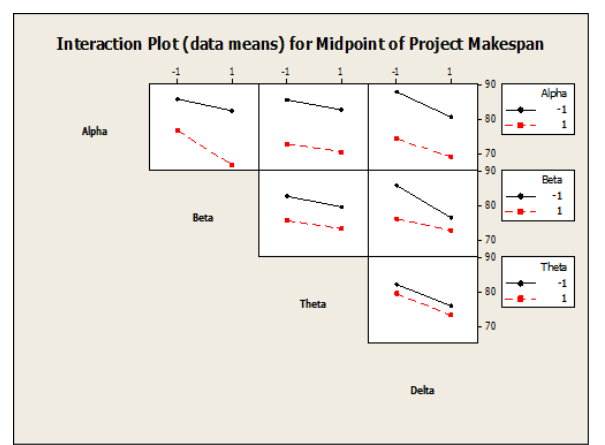

Figure 10: Interaction graphs on average project makespan.
In summary, the proposed approach is able to produce various crisp and interval-valued project schedules according to the project manager's attitude toward risk. One of the most impressive managerial insight of the produced solutions is that the proposed approach presents not only risky solutions for risk-seekers but also relatively more precise and risk-free solutions can be generated for risk-averse project managers. Therefore, more reliable and realizable solutions can be derived through the proposed approach. In detail, relatively more precise project schedules with longer makespan are produced for risk-averse or partially risk-averse project managers in construction industry. On the other hand, relatively shorter project makespan but more imprecise completion time intervals (or project schedules with high degree of uncertainty) are obtained for risk-seeking project managers. For a risk neutral project manager, completion time intervals of the activities have relatively lower degree of uncertainty. In other words, lower and upper bounds of the completion time interval of an activity are close to each other.

According to Table 6 and 7, computational complexity, CPU time and model size of the fully uncertain RCPSP increase dramatically when compared to the deterministic case. It is because of increases in the numbers of decision variables and constraints. Actually, this is mainly due to the fact that defining several time intervals as binary variables and additional constraints for handling risky situations. This may cause increases in the model dimension and CPU time of the solutions. Since the flexibility of risk parameters, optimal solution can be found easily within a reasonable computational time for a riskseeking project manager. When the values of different risk parameters are restricted, solution of the model will be more difficult and may take a longer CPU time for a risk-averse project manager as it is clearly seen in Table 7. For a riskneutral project manager, midpoint values of the risk parameters $(\alpha=\beta=0.5$ and $\theta=\Delta=\sqrt{2} / 2)$ are considered.

\section{Concluding remarks}

This paper presents a novel interval programming based transformation approach for solving a fully uncertain RCPSP. In a fully uncertain RCPSP, all of the project parameters including 
activity durations, the earliest/latest finishing times, resource requirements of the activities and available resource capacities are considered as uncertain. Under such a fully uncertain environment, interval-valued project schedules can be comparatively better than the currently available deterministic project schedules. For that reason, classical discrete-time binary integer mathematical formulation of the RCPSP is handled and modified under interval uncertainty. In the mathematical formulation, all of the project parameters as well as the project schedules are considered as interval numbers. Then in the solution phase of the problem, interval arithmetic operations are conducted by means of additional information to transform the fully uncertain RCPSP model into a crisp equivalent form. Actually, this information reflects the project manager's attitude toward risk. In the proposed transformation process, four different risky situations in project scheduling are taken into account and illustrated by a trivial numerical example. Then, the provided crisp equivalent model is solved by a classical optimization technique since it is reduced to an integer linear program. The applicability and practicality of the proposed approach are also tested on a real-life LNG storage tank construction project. According to the computational results, relatively more precise project schedules with larger makespan are produced for risk-averse and partially riskaverse project managers. On the other hand, relatively shorter makespan but more imprecise completion time intervals with high level of uncertainty are provided for risk-seeking project managers.

In this research paper, a transformation approach in which an interval program is first converted into its crisp equivalent form and then solved by a classical optimization technique is proposed. Such indirect solution approaches may cause loss of information during the transformation process of uncertainty [8]. Moreover, model dimension, i.e., number of constraints and decision variables, may generally increase due to the transformation operations. Additionally, due to the NP-hard nature of the fully uncertain RCPSP, complexity and computational time of the solution may increase dramatically. For all of these reasons, a direct solution approach without any interval to crisp transformation can be developed in the future based on a decoding algorithm within a metaheuristic application. Thus, the constrained interval arithmetic and ranking operations can also be performed within this decoding procedure. Such a metaheuristic based direct solution approach can also be used to solve large-sized realistic fully uncertain RCPSP instances within a reasonable computational time. Moreover, the proposed approach can be used just for a single mode RCPSP with interval-valued project parameters and variables. In the future, it can be extended to solve multimode RCPSP including fuzzy-stochastic parameters and variables since the real-life applications may involve different types of uncertainties simultaneously.

\section{References}

[1] Chen Z, Demeulemeester E, Bai S, Guo Y. "Efficient priority rules for the stochastic resource-constrained project scheduling problem". European Journal of Operational Research, 270(3), 957-967, 2018.

[2] Rostami S, Creemers S, Leus R. "New strategies for stochastic resource-constrained project scheduling". Journal of Scheduling, 21(3), 349-365, 2018.
[3] Atli O, Kahraman C. "Fuzzy resource-constrained project scheduling using taboo search algorithm". International Journal of Intelligent Systems, 27(10), 873-907, 2012.

[4] Atli O, Kahraman C. "Resource-constrained project scheduling problem with multiple execution modes and fuzzy/crisp activity durations". Journal of Intelligent \& Fuzzy Systems, 26(4), 2001-2020, 2014.

[5] Kahraman C, Kerre EE, Bozbura FT. Uncertainty modelling and in knowledge engineering and decision making. Proceedings of the 10 th International FLINS Conference, Istanbul, Turkey, 26-29 August 2012.

[6] Subulan K. "Fully uncertain resource constrained project scheduling problem via interval programming: a real-life application in a LNG storage tank construction". $2^{\text {nd }}$ International Conference on Economics Business Management and Social Sciences, Belgrade, Serbia, 10-14 May 2017.

[7] Baykasoğlu A, Subulan K. "Constrained fuzzy arithmetic approach to fuzzy transportation problems with fuzzy decision variables". Expert Systems with Applications, 81, 193-222, 2017.

[8] Baykasoğlu A, Subulan K. "A direct solution approach based on constrained fuzzy arithmetic and metaheuristic for fuzzy transportation problems". Soft Computing, https://doi.org/10.1007/s00500-017-2890-2.

[9] Malcolm DG, Rosenbloom JM, Clark CE, Fazar W. "Application of a technique for research and development program evaluation". Operations Research, 7, 646-669, 1959.

[10] Jørgensen T. Project Scheduling as a Stochastic Dynamic Decision Problem. PhD Thesis, Norwegian University of Science and Technology, Trondheim, Norway, 1999.

[11] Artigues C, Leus R, Nobibon FT. "Robust optimization for resource-constrained project scheduling with uncertain activity durations". Flexible Services and Manufacturing Journal, 25, 175-205, 2013.

[12] Li H, Womer NK. "Solving stochastic resource-constrained project scheduling problems by closed-loop approximate dynamic programming". European Journal of Operational Research, 246, 20-33, 2015.

[13] Perez M. A simulation based optimization approach for stochastic resource constrained project management with milestones. MSc Thesis, Rochester Institute of Technology, New York, USA, 2015.

[14] Ashtiani B, Leus R, Aryanezhad MB. "New competitive results for the stochastic resource-constrained project scheduling problem: exploring the benefits of pre-processing". Journal of Scheduling, 14(2), 157-171, 2011.

[15] Wang L, Huang H, Ke H. "Chance-Constrained model for RCPSP with uncertain durations". Journal of Uncertainty Analysis and Applications, 12(3), 1-10, 2015.

[16] Tseng CC, Ko PW. "Measuring schedule uncertainty for a stochastic resource-constrained project using scenariobased approach with utility-entropy decision model". Journal of Industrial and Production Engineering, 33(8), 558-567, 2016.

[17] Creemers S. "The preemptive stochastic resourceconstrained project scheduling problem: an efficient globally optimal solution procedure". Working paper KBI_1626. KU Leuven, Faculty of Economics and Business, Department of Decision Sciences and Information Management, 2016. 
[18] Chakrabortty RK, Sarker RA, Essam DL. "Resource constrained project scheduling with uncertain activity durations". Computers \& Industrial Engineering, 112, 537-550, 2017.

[19] Bruni ME, Pugliese LDP, Beraldi P, Guerriero F. "An adjustable robust optimization model for the resource-constrained project scheduling problem with uncertain activity durations". Omega, 71, 66-84, 2017.

[20] Bruni ME, Pugliese LDP, Beraldi P, Guerriero F. "A computational study of exact approaches for the adjustable robust resource-constrained project scheduling problem". Computers \& Operations Research, 99, 178-190, 2018.

[21] Chand S, Singh HK, Ray T. "Finding robust solutions for resource constrained project scheduling problems involving uncertainties". 2016 IEEE Congress on Evolutionary Computation (CEC), Vancouver, Canada, 24-29 July 2016.

[22] Uysal F, Işleyen SK, Çetinkaya C. "Resource constrained project scheduling with stochastic resources". Journal of Applied Research on Industrial Engineering, 5(1), 39-49, 2018.

[23] Hapke M, Jaszkiewicz A, Slowinski R. "Fuzzy project scheduling system for software development". Fuzzy Sets Systems, 21, 101-117, 1994.

[24] Hapke M, Slowinski R. "Fuzzy priority heuristics for project scheduling". Fuzzy Sets Systems, 83, 291-299, 1996.

[25] Ozdamar L, Alanya E. "Uncertainty modelling in software development projects (with case study)". Annals of Operations Research, 102(1-4), 157-178, 2001.

[26] Pan, H, Willis, RJ, Yeh CH. Resource constrained project scheduling with fuzziness". Advances in Fuzzy Systems and Evolutionary Computation, WSEAS Press, 173-179, 2001.

[27] Pan $\mathrm{H}$, Yeh CH. "Fuzzy project scheduling". The $12^{\text {th }}$ IEEE International Conference on Fuzzy Systems, St Louis, USA, 25-28 May 2003.

[28] Liu S, Yung KL, Ip WH. "Genetic local search for resourceconstrained project scheduling under uncertainty". Information and Management Sciences, 18(4), 347-363, 2007.

[29] Long LD, Ohsato A. "Fuzzy critical chain method for project scheduling under resource constraints and uncertainty". International Journal of Project Management, 26(6), 688698, 2008.

[30] Bhaskar T, Pal MN, Pal AK. "A heuristic method for RCPSP with fuzzy activity times". European Journal of Operational Research, 208, 57-66, 2011.

[31] Wang X, Huang W. "Fuzzy resource-constrained project scheduling problem for software development". Wuhan University Journal of Natural Sciences, 15(1), 25-30, 2010.

[32] Kaveh A, Khanzadi M, Alipour M. "Fuzzy resource constraint project scheduling problem using cbo and css algorithms". International Journal of Civil Engineering, 14(5), 325-337, 2016

[33] Sajadi SM, Azimi P, Ghamginzadeh A, Rahimzadeh A. "A new fuzzy multi-objective multi-mode resourceconstrained project scheduling model". International Journal of Mathematics in Operational Research, 11(1), 45-66, 2017.

[34] Wang J. "A fuzzy project scheduling approach to minimize schedule risk for product development". Fuzzy Sets and Systems, 127(2), 99-116, 2002.
[35] Wang J. "A fuzzy robust scheduling approach for product development projects". European Journal of Operational Research, 152, 180-194, 2004.

[36] Masmoudi M, Hait A. "Project scheduling under uncertainty using fuzzy modelling and solving techniques". Engineering Applications of Artificial Intelligence, 26, 135-149, 2013.

[37] Zha H, Zhang L. "Fuzzy flexible resource constrained project scheduling based on genetic algorithm". Transactions of Tianjin University, 20(6), 469-474, 2014.

[38] Knyazeva M, Bozhenyuk A, Rozenberg I. "Resourceconstrained project scheduling approach under fuzzy conditions". Procedia Computer Science, 77, 56-64, 2015.

[39] Yousefli A. "A fuzzy ant colony approach to fully fuzzy resource constrained project scheduling problem". Industrial Engineering \& Management Systems, 16(3), 307-315, 2017.

[40] Nematian J, Eshghi K, Eshragh-Jahromi A. "A resourceconstrained project scheduling problem with fuzzy random duration". Journal of Uncertain Systems, 4(2), 123132, 2010.

[41] Bellman R, Zadeh LA. "Decision-making in a fuzzy environment". Management Science, 17, 141-164, 1970.

[42] Artykov D, Atymtayeva L. "A fuzzy linear programming approach for resource-constrained project scheduling". Advanced Engineering Technology and Application, 4(3), 47-52, 2015.

[43] Xu Z, Zhang Z. "A fuzzy random resource-constrained scheduling model with multiple projects and its application to a working procedure in a large-scale water conservancy and hydropower construction project". Journal of Scheduling, 15, 253-272, 2012.

[44] Gang J, Xu J, Xu Y. “Multiproject resources allocation model under fuzzy random environment and its application to industrial equipment installation engineering". Journal of Applied Mathematics, Article ID 818731, 1-19, 2013.

[45] Zhang Z. "A MODM bi-level model with fuzzy random coefficients for resource-constrained project scheduling problems". Seventh International Joint Conference on Computational Sciences and Optimization (CSO), Beijing, China, 4-6 July 2014.

[46] Xu J, Feng C. "Multimode resource-constrained multiple project scheduling problem under fuzzy random environment and its application to a large scale hydropower construction project". The Scientific World Journal, Article ID 463692, 1-20, 2014.

[47] Chen L, Zhang Z. "Preemption resource-constrained project scheduling problems with fuzzy random duration and resource availabilities". Journal of Industrial and Production Engineering, 33(6), 373-382, 2016.

[48] Xu ZS. "On multi-period multi-attribute decision making". Knowledge-Based Systems, 21, 164-171, 2008.

[49] Yue Z. "An extended TOPSIS for determining weights of decision makers with interval numbers". KnowledgeBased Systems, 24(1), 146-153, 2011.

[50] Li M, Fu Q, Singh VP, Liu D. “An interval multi-objective programming model for irrigation water allocation under uncertainty". Agricultural Water Management, 196, 24-36, 2018.

[51] Dawood H. Theories of Interval Arithmetic: Mathematical Foundations and Applications. Saarbrücken, Germany, LAP Lambert Academic Publishing, 2011. 
[52] Li D, Zeng W, Yin Q. "Novel ranking method of interval numbers based on the Boolean matrix". Soft Computing, 22, 4113-4122, 2018.

[53] Zuras D, Hayes NT. "Midpoint and unbounded intervals". http://grouper.ieee.org/groups/1788/email/pdf26UeyT cNEW.pdf (30.07.2018).

[54] Sengupta A, Pal TK. "On comparing interval numbers". European Journal of Operational Research, 127, 28-43, 2000.

[55] Sengupta A, Pal TK, Chakraborty D. "Interpretation of inequality constraints involving interval coefficients and a solution to interval linear programming". Fuzzy Sets and Systems, 119, 129-138, 2001.

[56] Gani AN, Assarudeen SNM. "A new operation on triangular fuzzy number for solving fuzzy linear programming problem". Applied Mathematical Sciences, 6, 525-532, 2012.

[57] Klir GJ, Cooper JA. "On constrained fuzzy arithmetic". Proceedings of 5th international IEEE conference on fuzzy systems, New Orleans, USA, 11 September 1996.

[58] Klir GJ, Pan Y. "Constrained fuzzy arithmetic: basic questions and some answers". Soft Computing, 2, 100-108, 1998.

[59] Klir GJ. "Fuzzy arithmetic with requisite constraints". Fuzzy Sets Systems, 91, 165-175, 1997.

[60] Lodwick WA. "Constrained interval arithmetic". Department of Mathematics, Colorado University, Denver, USA, CCM Report, 138, 1999.

[61] Lodwick WA, Untiedt EA. "A comparison of interval analysis using constraint interval arithmetic and fuzzy interval analysis using gradual numbers". NAFIPS 2008Annual Meeting of the North American Fuzzy Information Processing Society, New York, USA, 19-22 May 2008.
[62] Pritsker A, Watters L, Wolfe P. "Multi-project scheduling with limited resources: a zero-one programming approach". Management Science, 16, 93-108, 1969.

[63] Uysal MP. "An empirical study in software engineering: the effects of project-based and project-supported methods on product and academic achievements". Pamukkale University Journal of Engineering Sciences, 24(2), 226-237, 2018.

[64] Gür Ş, Hamurcu M, Eren T. "Selecting of Monorail projects with analytic hierarchy process and 0-1 goal programming methods in Ankara". Pamukkale University Journal of Engineering Sciences, 23(4), 437-443, 2017.

[65] Subulan K, Saltabas A, Tasan AS, Girgin SC. "Modeling and analyzing of a construction project considering resource allocation through a hybrid methodology: petri nets and fuzzy rule based systems". Proceedings of the 41st International Conference on Computers \& Industrial Engineering, California, USA, 23-25 October 2011.

[66] Akboga O, Percin SS, Baradan S, Girgin SC. "A comparative study on the influence of cultural differences on project duration in international construction projects". $9^{\text {th }}$ International Congress on Advances in Civil Engineering, Trabzon, Turkey, 27-30 September 2010.

[67] The Observer. "Hot Topic News". https://www.gladstoneobserver.com.au/videos/roofraised-huge-lng-tank/17461/ (06.08.2018).

[68] Nippon Steel \& Sumitomo Metal Corporation. "Press Release". http://www.nssmc.com/en/news/20140619_100.html (06.08.2018). 